\title{
RURAL WOMEN S ADOPTION OF SAFETY HOME BREEDING RECOMMENDATIONS OF CHICKENS TO LIMIT BIRDS FLU SPREAD IN TWO VILLAGES IN EL BEHIRA GOVERNORAT
}

El-Zarka, Z. M. and A. A. A. Fayed and M. I. A.Hassan

Faculty of Agricultural , Damanhour University

تبنى الريفيات للتوصيات الإرشادية للتربية المنزلية السليمة للاجاج للحد من انتثـار

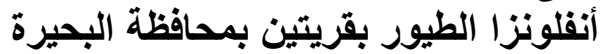
زكريا محمدالزرقا ، أمل عبد الرسول أحمد فايد ومحمد إبراهيم عبد اليد الحميد حسن كلية الزراعة - جامعة دمنهور

\section{الملخص}

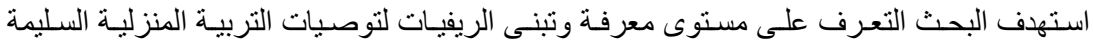

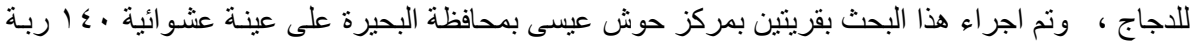

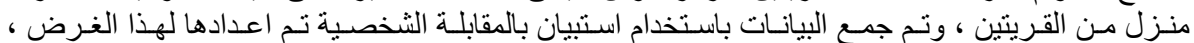

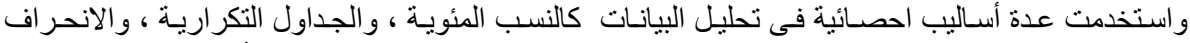

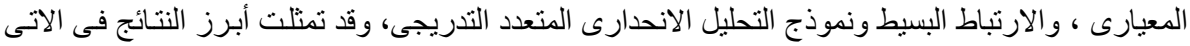

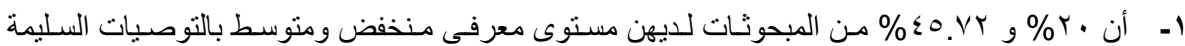

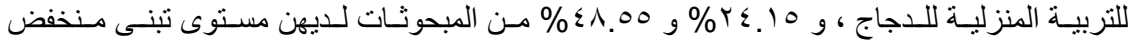

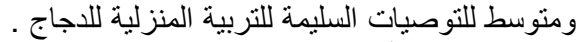

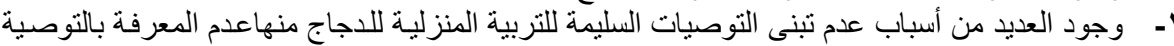

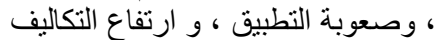

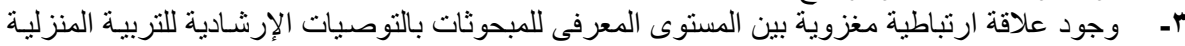

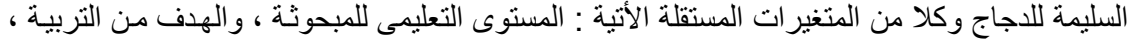

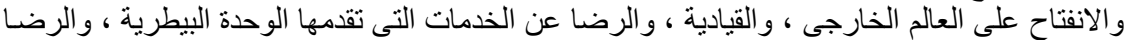

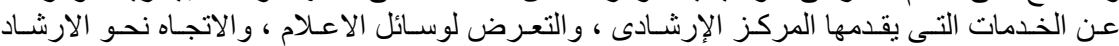

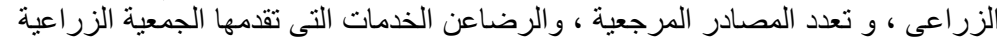

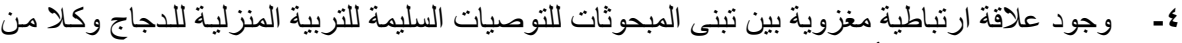

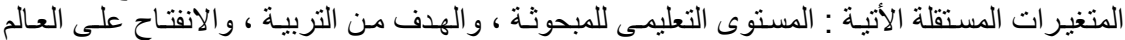

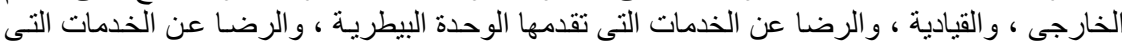

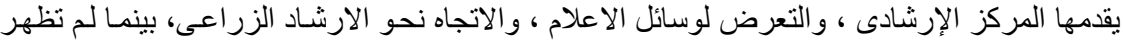

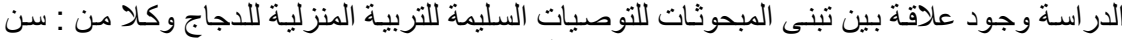

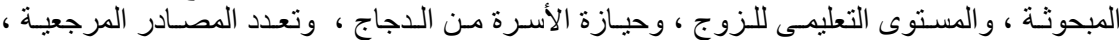

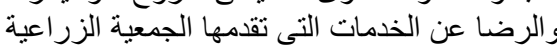

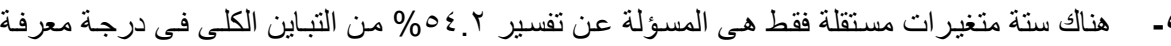

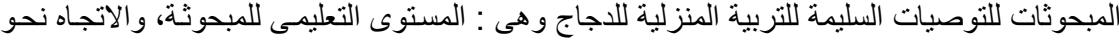

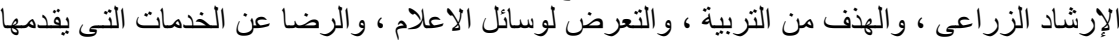

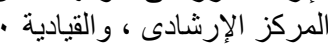

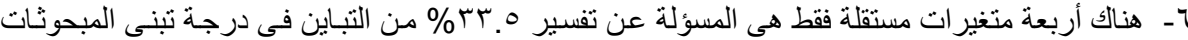

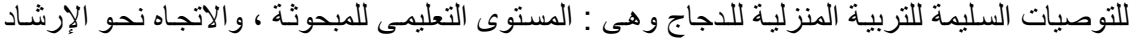

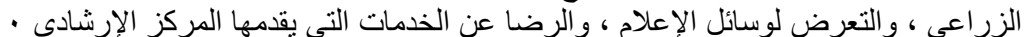

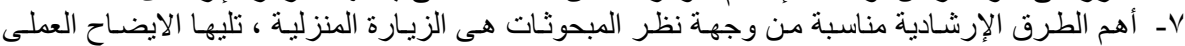

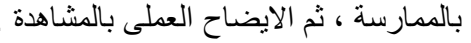




\section{المقدمة والمثكلة البحثية}

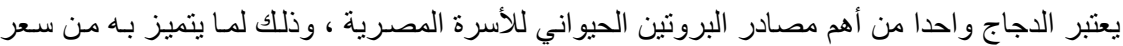

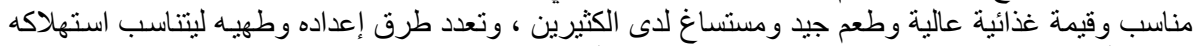
للجميع أو الغالبية العظمى من السكان سواء فى الريف أو الحضر وخاصة ونطية الطبقة المتوسطة و والمحدودة الدخل

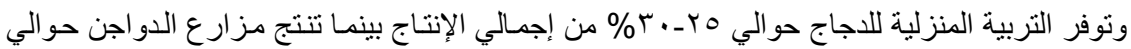

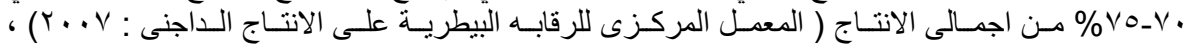

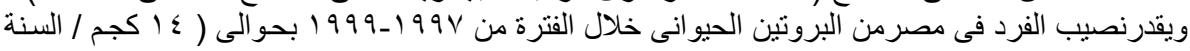

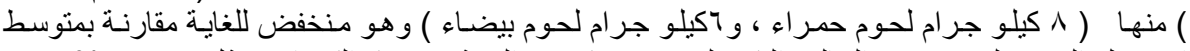

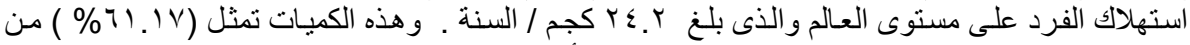

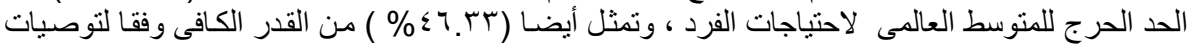

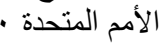

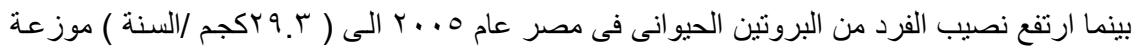

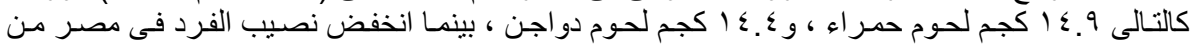

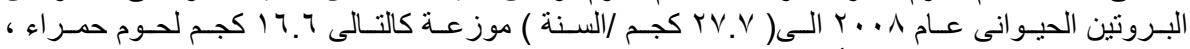

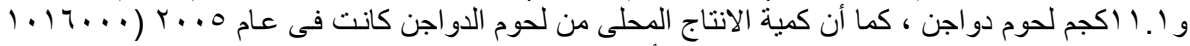

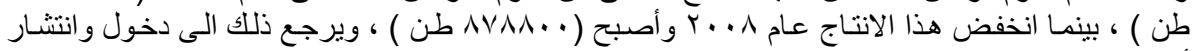

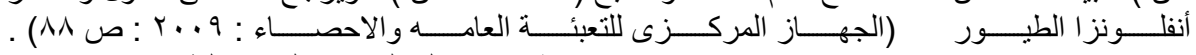

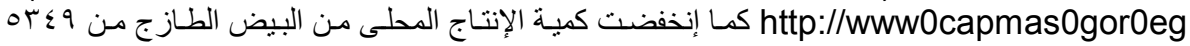

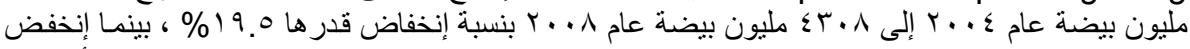

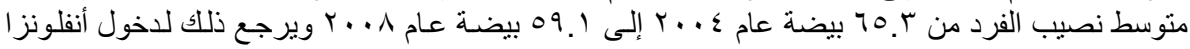

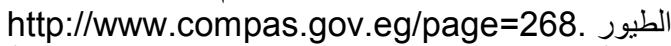

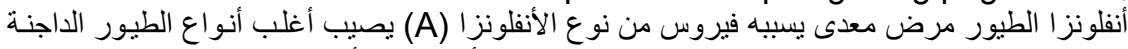

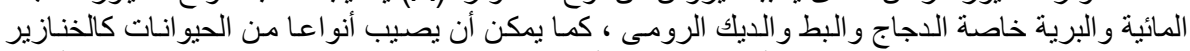

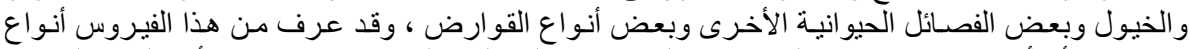

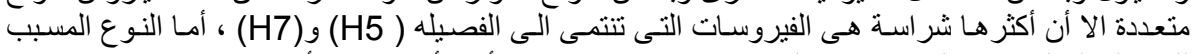

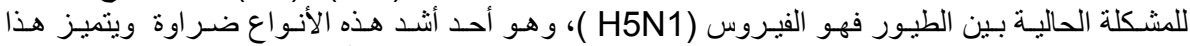

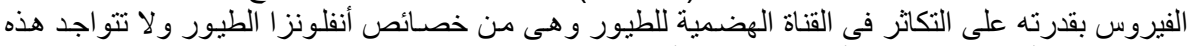

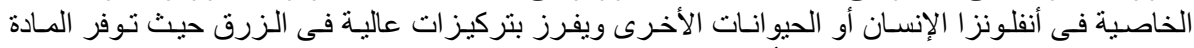

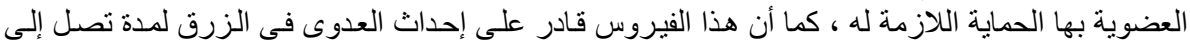

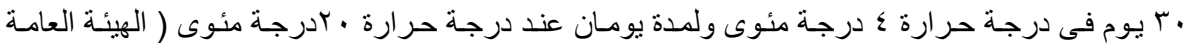

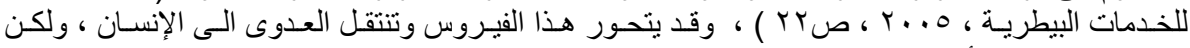

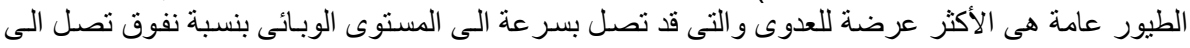

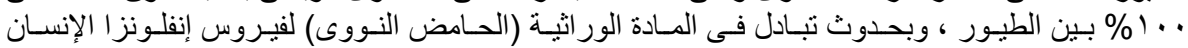

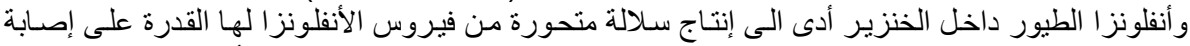

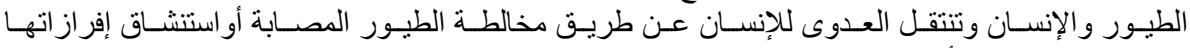

.http://www.alhadeeqa.com/vb/showthread.php?t=1902

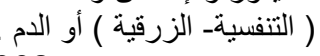

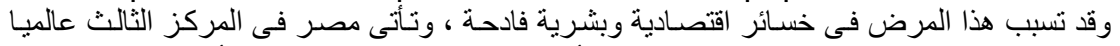

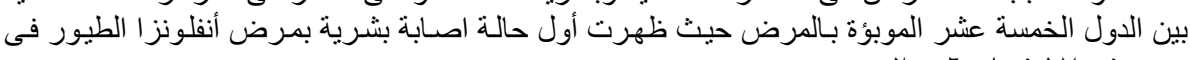

http://www.dakahliaikhwan.com/viewarticle.php?id=1766

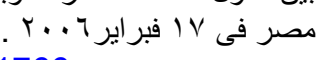

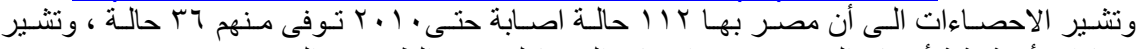

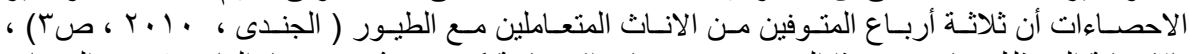

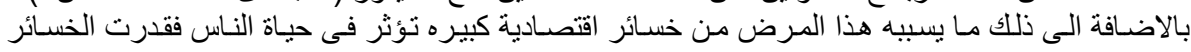

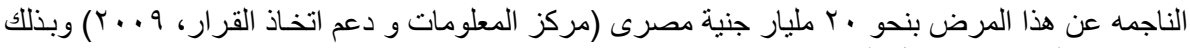

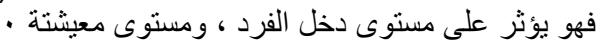




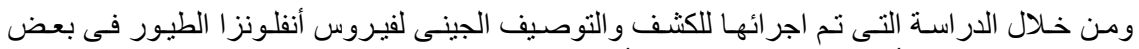

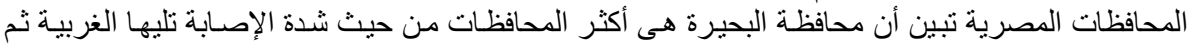

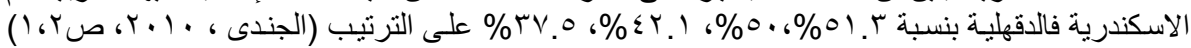

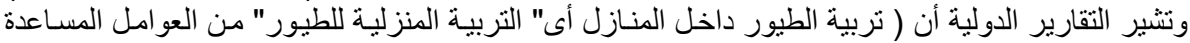

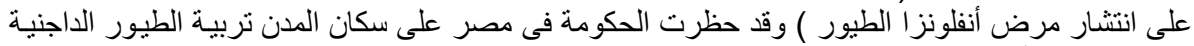

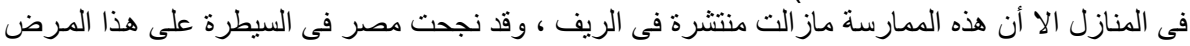

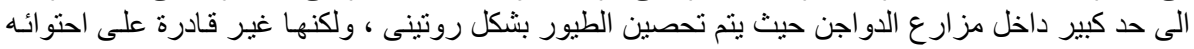

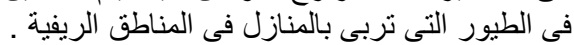

http://www.libya-alyoum.com/look/article?Idlanguage=178ldp..2008

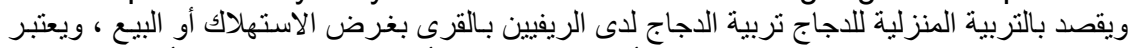

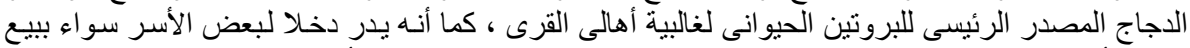

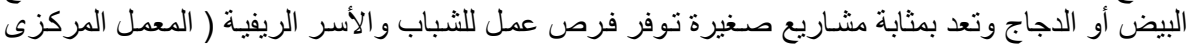

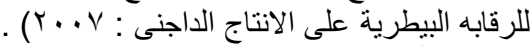

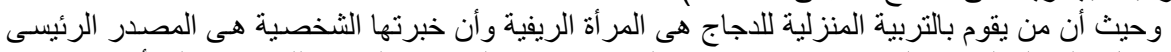

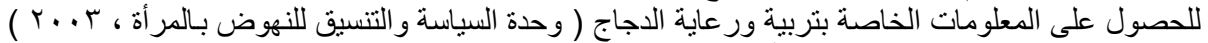

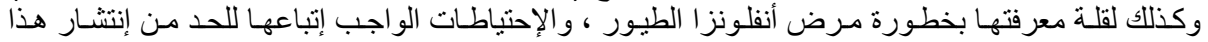

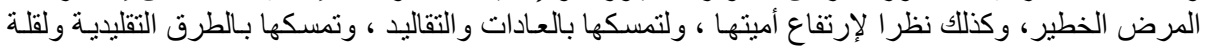

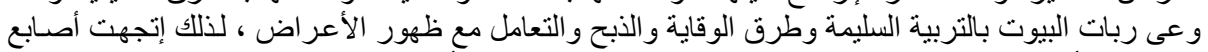

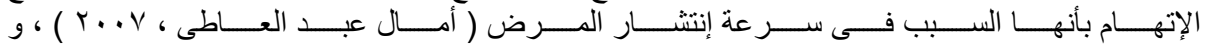

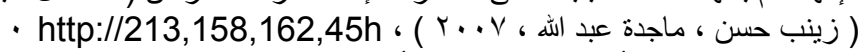

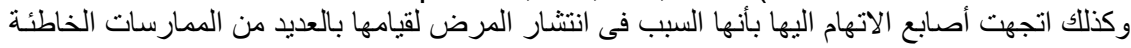

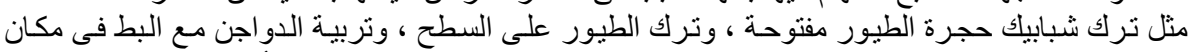

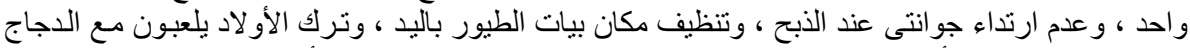

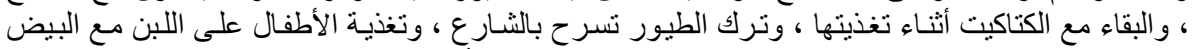

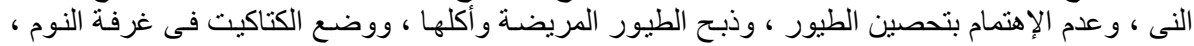

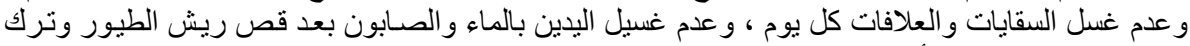

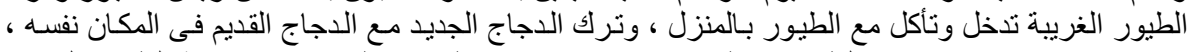

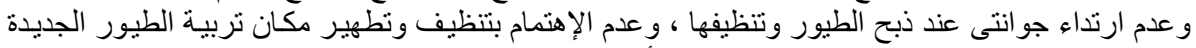

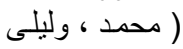

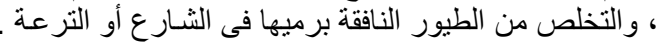

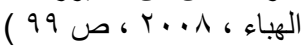
وبر غم أن القانون يسمح بتربية الطيور فى المنازل داخل المناطق الريفية، لكن يجب أنس أن يتم ذلك بصورة

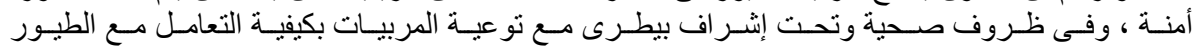

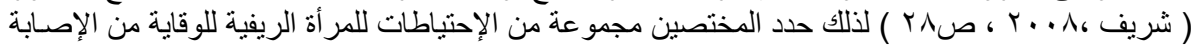

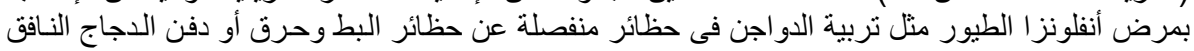

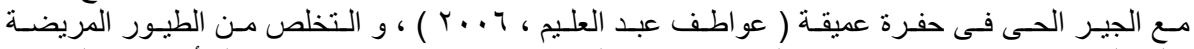

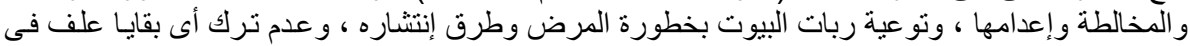

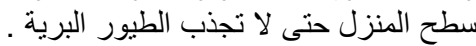
http://www.as7apcool.com/vb/showthread.php?t=230812

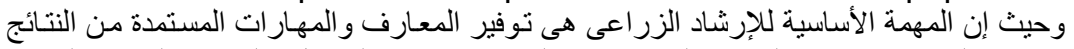

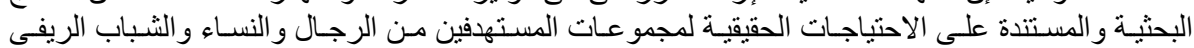

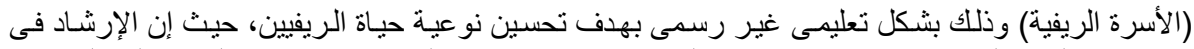

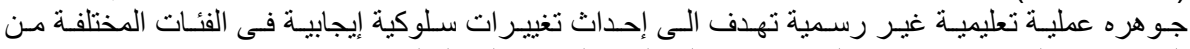

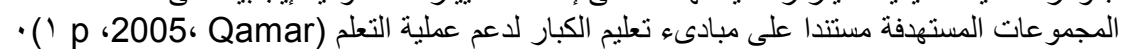

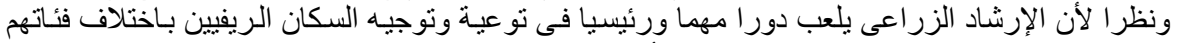

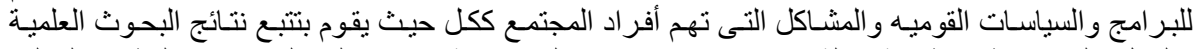

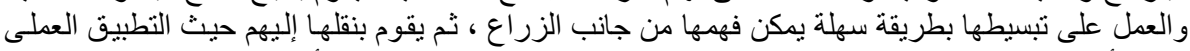

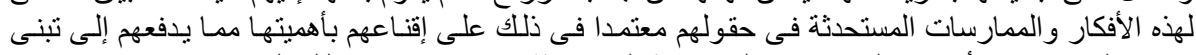

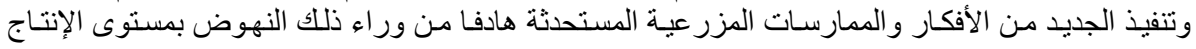




\section{El-Zarka, Z. M. et al.}

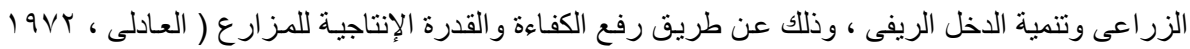

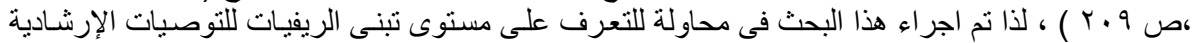

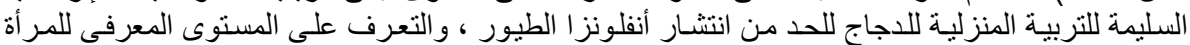

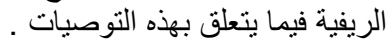
أهداف البحث استهدف البحث التعرف على تبنى الريفيات للتوصيات الإرشـادية للتربيـة المنزلية السليمة للـاجاج للحد من

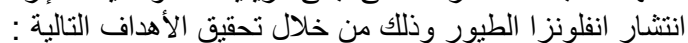

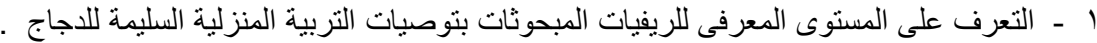

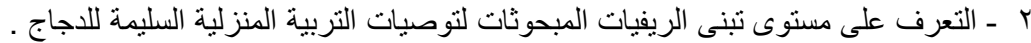

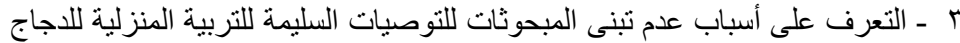

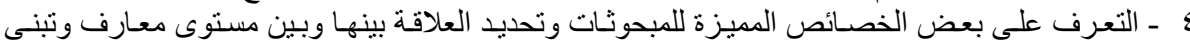

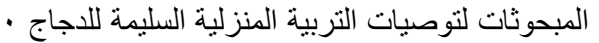

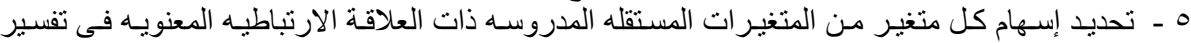
مستوى معارف وتبنى المبحوثات لتوصيات التربية المنزلية السليمة للاجاج

\section{الطريقة البحثية}

\section{التعاريف الإجرائية :}

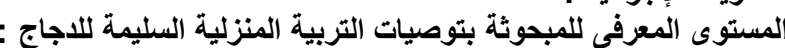

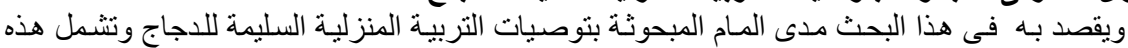

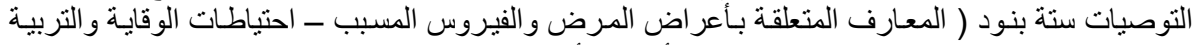

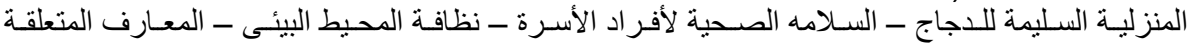

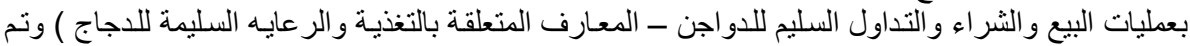

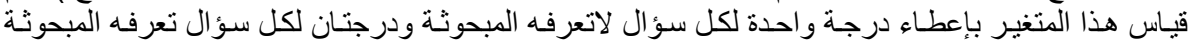

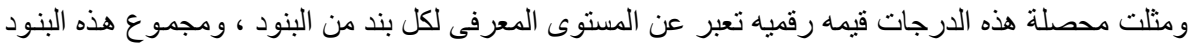

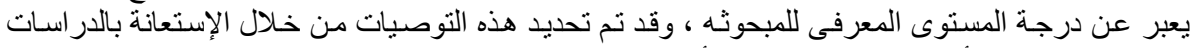

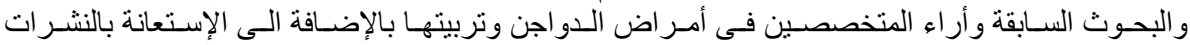

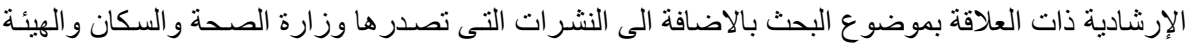
العامة للخدمات البيطرية.

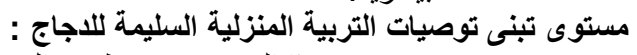

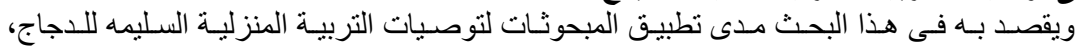

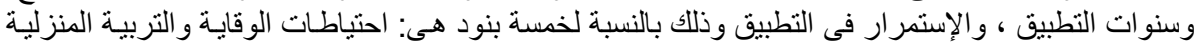

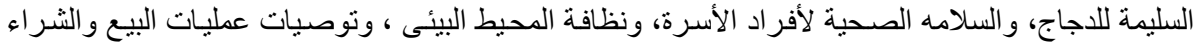

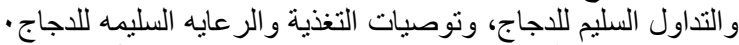

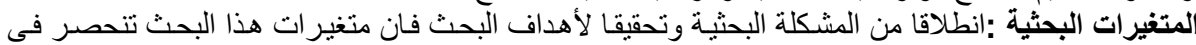

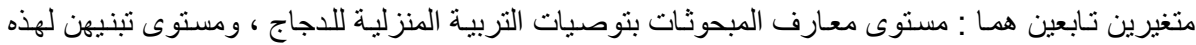

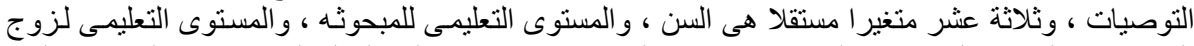

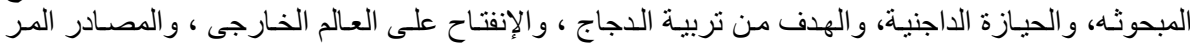

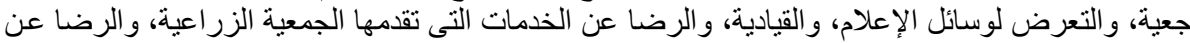

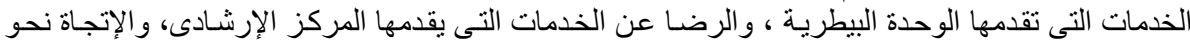

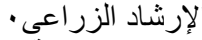
الفروض البحثية :وفي" الأهداف البحث وفى ضوء ما ما نم استعر اضـه من نتائج بحوث ودر اسـات سـابقة فان هذا

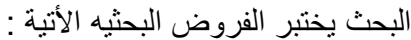
ا ـ توجد علاقة ارتباطية بين مستوى معرفة المبحثة البحوثات بتوصيات التربية المنزلية السليمة للاجاج وبين كل من

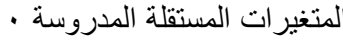
r - توجد علاقة ارتباطية بين مستوى تبنى المبحوثات لتوصئنيات التربية المنزلية السليمة للاجاج وبين كل من

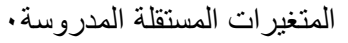




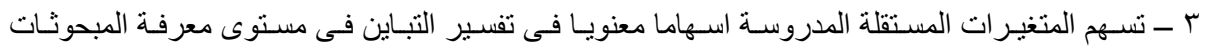

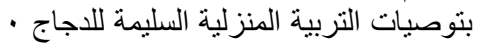

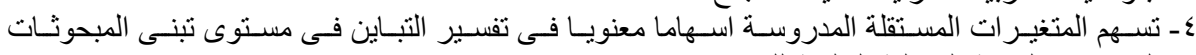

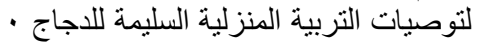

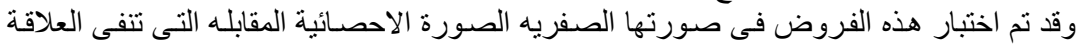

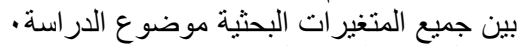
منطقة وشاملة وعينة البحثث

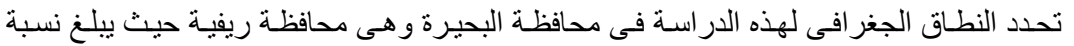

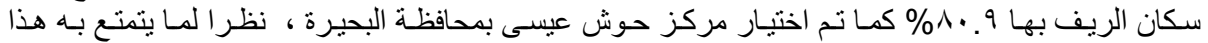

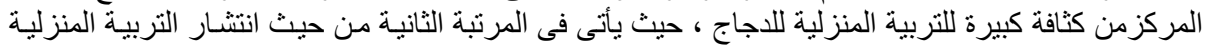

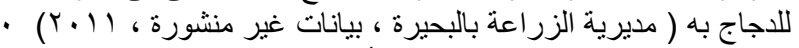

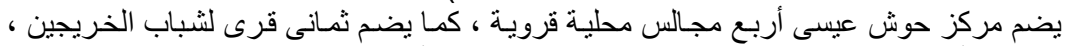

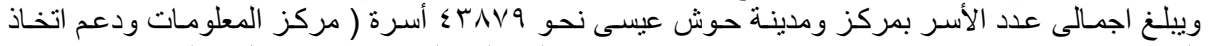

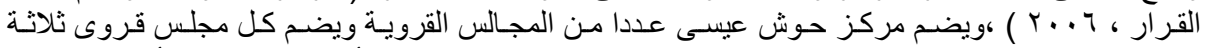

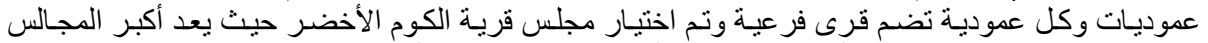

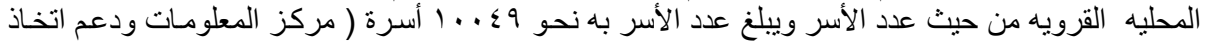

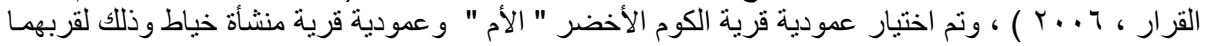

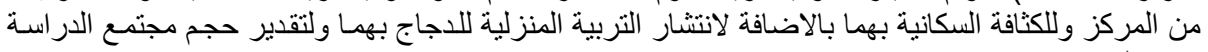

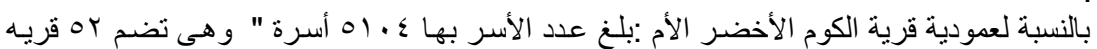

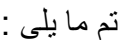

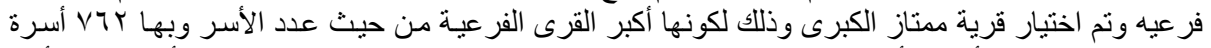

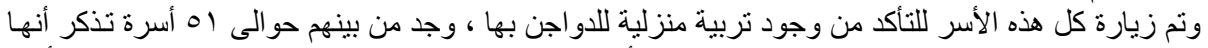

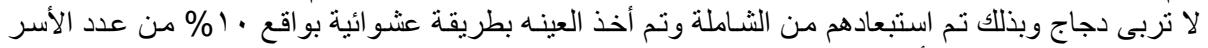

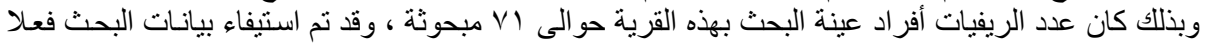

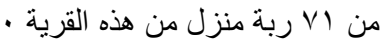

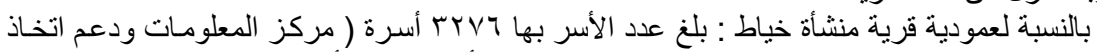

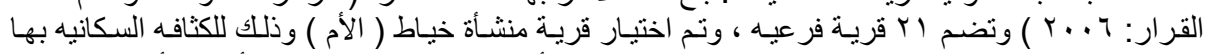

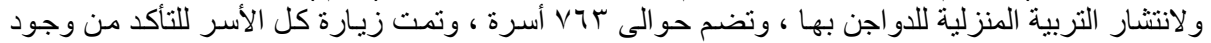

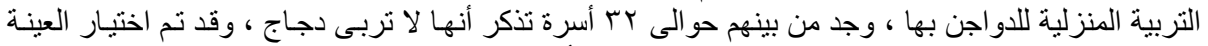

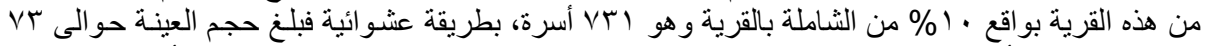

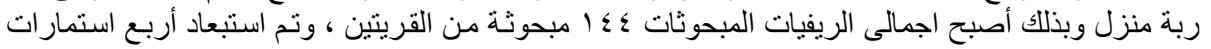

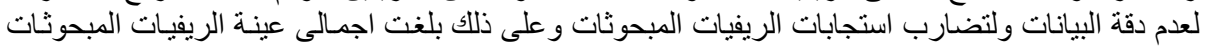

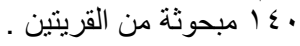
تجميع وتحليل البيانات :

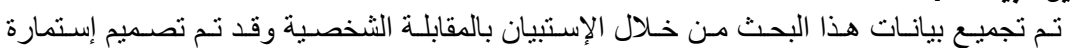

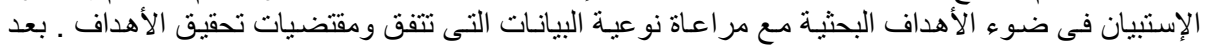

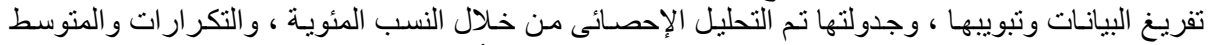

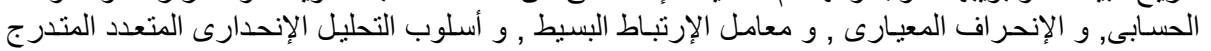

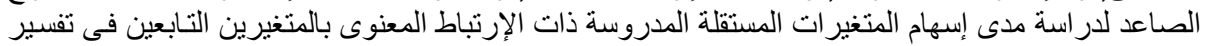

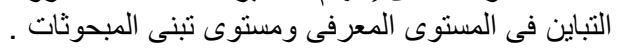

\section{النتائج ومناقثتنها}

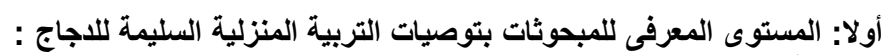

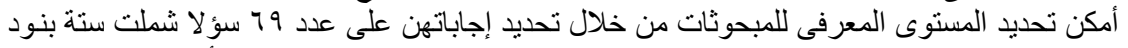

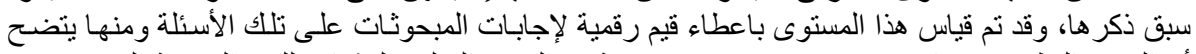

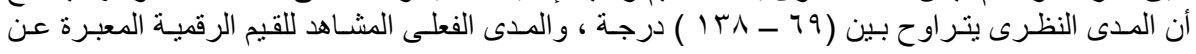


El-Zarka, Z. M. et al.

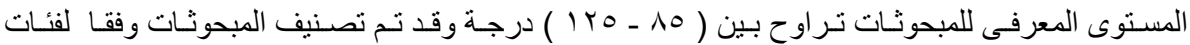

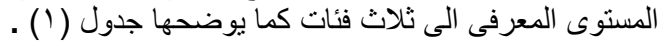

جدول ( ) : توزيع المبحوثات وفقا لمستوى معارفهن بتوصيات التربية المنزلية السليمة للاجاج

\begin{tabular}{|c|c|c|}
\hline$\%$ & 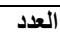 & قفنات المستوى المعرفى ( درجة ) \\
\hline$r$. & YA & ينخفض (rو فأَلَ) \\
\hline$\varepsilon 0 . Y Y$ & $T \varepsilon$ & وتوسط (من ra- 110) \\
\hline rE.YA & $\sum \lambda$ & مرتفع ( (1 (1 فاكثر) \\
\hline$\ldots$ & $1 \leqslant$. & جموع \\
\hline
\end{tabular}

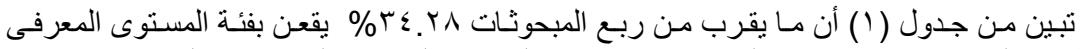

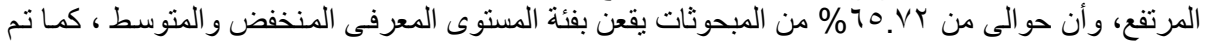

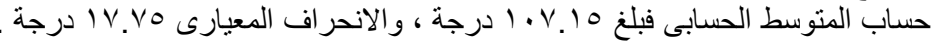
وفيما يلى استعر اض للمستوى المعرفى للمبحوثات لكل بند من بنود المعرفه :

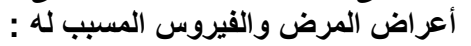

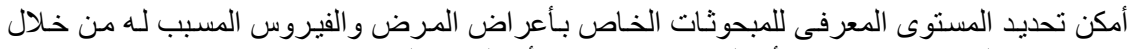

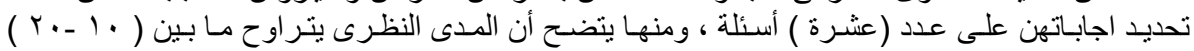

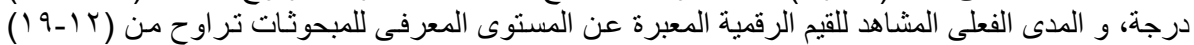

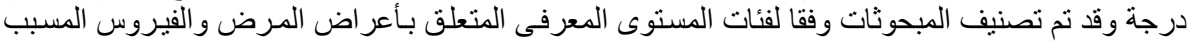

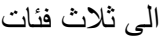

\begin{tabular}{|c|c|c|}
\hline$\%$ & العدد & ففنات المستوى المعرفي ( درجة ) \\
\hline IV.AY & ro & منخفض (rا فأقل) \\
\hline$r q . Y \Lambda$ & 00 & (IV-I) \\
\hline$\sum \varepsilon_{.10}$ & 7. & مرتفع ( (1 فأكثر ) \\
\hline $1 .$. & $1 \leqslant$. & ل لمجموع \\
\hline
\end{tabular}

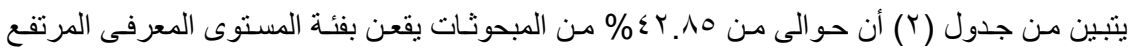

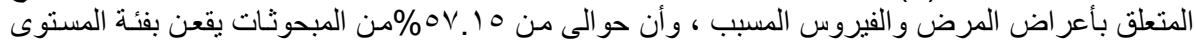

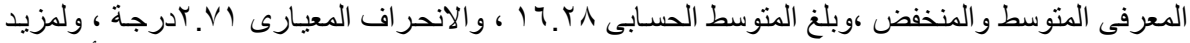

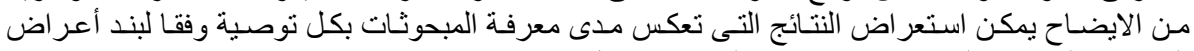

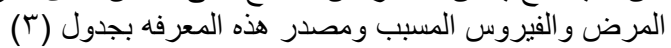

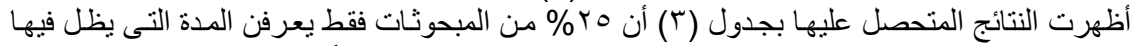

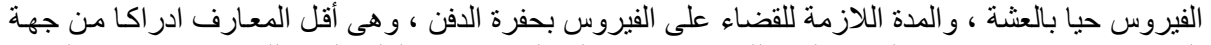

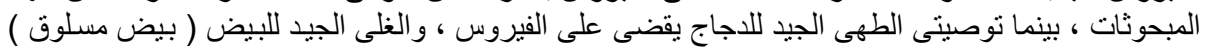

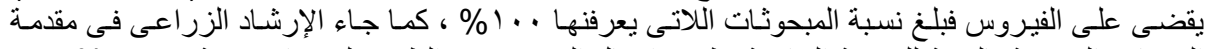

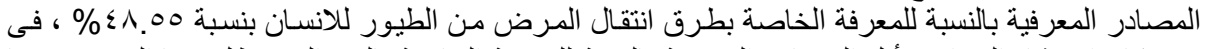

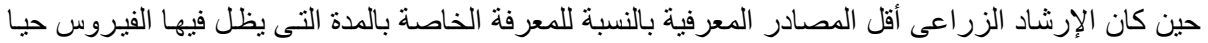

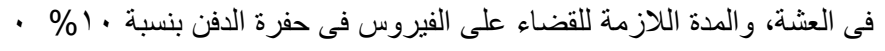

جدول(r): توزيع المبحوثات وفقا لمعارفهن بأعر اض المرض والفيروس المسبب له ، ومصدر هذه المعرفه

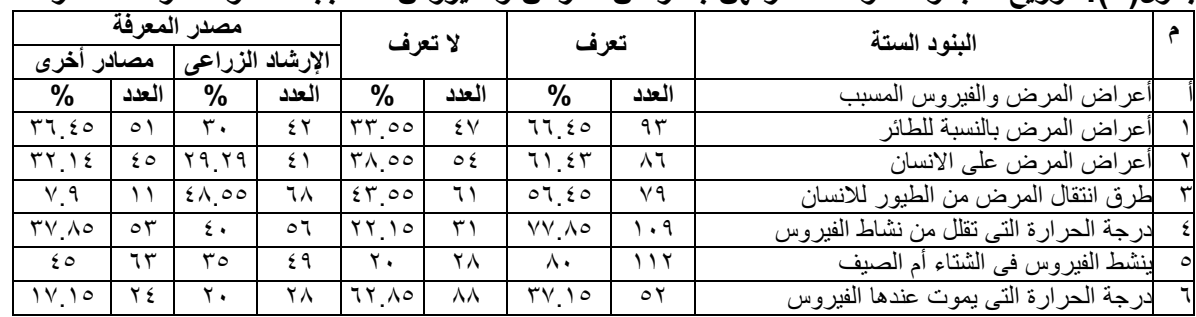


J. Agric. Econom. and Social Sci., Mansoura Univ., Vol.3 (2), February, 2012

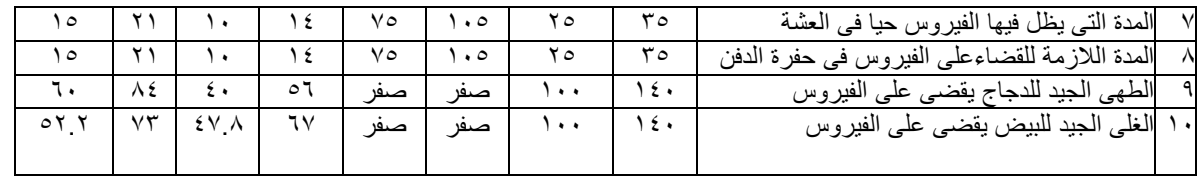

احتياطات الوقاية والتربية المنزلية السليمة للاجاج :

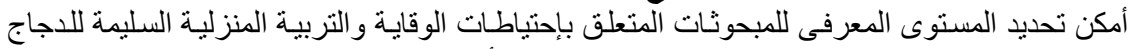

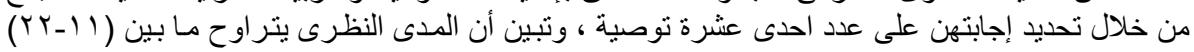

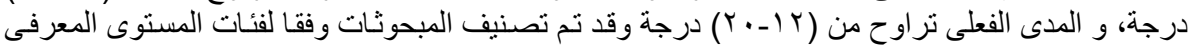

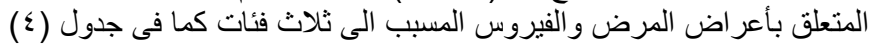

جدول (؛): توزيع المبحوثات وفقا لمستوى معارفهن باحتياطات الوقايه والتربية المنزلية السليمة

\begin{tabular}{|c|c|c|}
\hline$\%$ & العدد & فئات المستّوى المعرفي (درجة ) \\
\hline ro & ro & منخفض (10 فأقلّل ) \\
\hline $7 . . \wedge$ & 10 & هتوسط (7 (19-1) \\
\hline $1 \leqslant . Y$ & r. & مرتفع (·ץ فأكثر) \\
\hline $1 \cdots$ & $1 \leqslant \cdot$ & المجموع \\
\hline
\end{tabular}

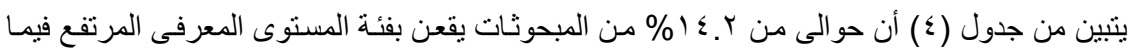

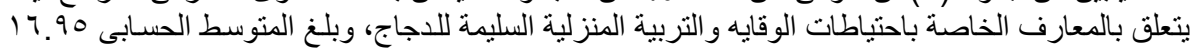

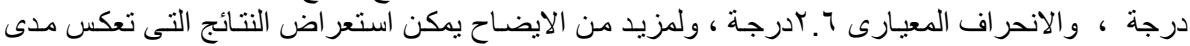

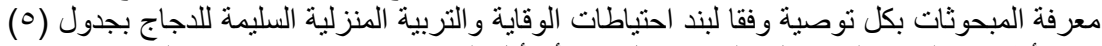

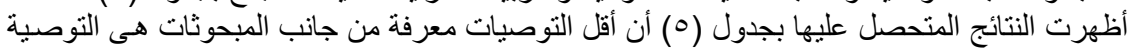

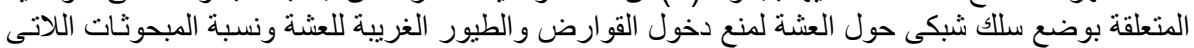

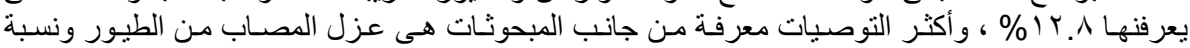

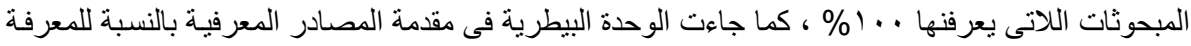

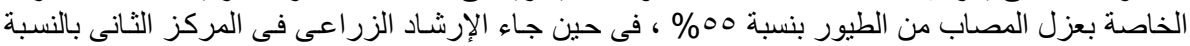

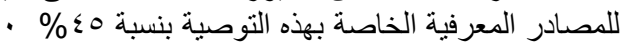

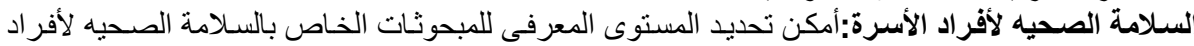

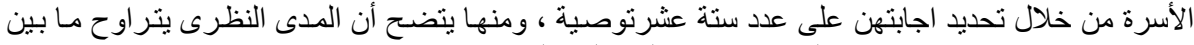

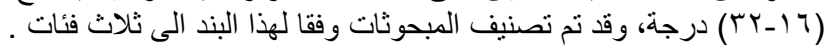

جدول (0): توزيـع المبحوثـات وفقـا لمعـارفهن بإحتياطـات الوقايـة والتربيـة المنزليـة الأمنـة ومصدر هذه

\begin{tabular}{|c|c|c|c|c|c|c|c|c|c|}
\hline & & & & & & & & | - مالمعرقه & \\
\hline & 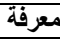 & مصدر & & يرف & & & & البند & \\
\hline 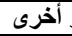 & مصاد & 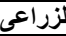 & الإرشاد & & & & & & \\
\hline$\%$ & العلد & $\%$ & العدد & $\%$ & العدد & $\%$ & العدد & احتياطات الوقاية و التربية & \\
\hline 00 & VV & $\leqslant 0$ & $\pi$ & | صفر & 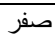 & $1 \ldots$ & $1 \varepsilon$. & عزل المصاب من الطيور & \\
\hline$\sum \uparrow . \varepsilon$ & 70 & $\varepsilon r . T$ & T) & 1. & $T \leqslant$ & 9. & $1 \times 4$ & وضع العشة فى مكان منفصل عن مكان معيشة أهل المنزل & \\
\hline$\varepsilon$. & 07 & ๘. & 07 & r. & rA & A. & $11 \mathrm{r}$ & |التثميس الجيد للحظائر و العشش & \\
\hline$\varepsilon \cdot$ & 07 & r & $\varepsilon r$ & r. & $\varepsilon r$ & $\mathrm{v} \cdot$ & 91 & وقف التربية مدة(r-ـ أسابيع ) فى الأماكن التى سبق اصابتها| & \\
\hline ro.1 & 0 . & $r \leqslant . r$ & $\Gamma \leq$ & «. & 07 & 7 & $\Lambda \Sigma$ & تربية الطبور فى عشش مسقوفة وجيدة التهوية & \\
\hline$r . \varepsilon$ & $\varepsilon \varepsilon$ & ro & ro & $\varepsilon r . \wedge 0$ & 71 & 07.10 & v9 & عدم تربية الطيور المشتراة حديثا مع الطيور المرباة بالمنزل & \\
\hline rฯ.气 & 01 & 10 & $\overline{Y T}$ & $\sum \wedge .00$ & 71 & $01 . \leqslant 0$ & VY & ابلاغ الوحدة ألبيطرية عند ملاحظة حدوث أعر اض مرضيةً & \\
\hline A.V & 15 & r & YA & $V I . \leqslant 0$. & $1 .$. & rA.00 & $\varepsilon \cdot$ & تحصين الطيور & \\
\hline $1 \mathrm{ir} .1$ & 19 & $1 \cdot . \mathrm{V}$ & 10 & vo. $\mathrm{Y}$ & 1.7 & $r \leqslant . r$ & $r \varepsilon$ & الامتناع عن تربية الطيور فى العراء أو & \\
\hline$r . \Lambda$ & 11 & 1. & $1 \varepsilon$ & \begin{tabular}{|l|}
$V V . Y$ \\
\end{tabular} & 1.1 & rY.A & rr & 4 & \\
\hline
\end{tabular}


El-Zarka, Z. M. et al.

\begin{tabular}{|c|c|c|c|c|c|c|c|c|c|c|}
\hline $1 \cdot$ & $1 \xi$ & r.^ & . & Av. & T) & r & Ir. & & 11 & 1 إ. وضع سلك شبكى على جو انب العشة لمنع دخول القوارض \\
\hline
\end{tabular}

جدول (T): توزيع المبحوثات وفقا لمستوى معارفهن بالسلامة الصحية لأفراد الأسرة

\begin{tabular}{|c|c|c|}
\hline$\%$ & العدد & قُئات المستوى المعرفى ( درجة ) \\
\hline صفر & صفر & منذفض( آفأقلّل) \\
\hline $7 \varepsilon . Y$ & 9. & 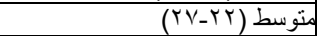 \\
\hline ro.A & 0. & مرتفع (1) فأكثر ) \\
\hline $1 \ldots$ & $1 \leqslant$. & |لمجموع \\
\hline
\end{tabular}

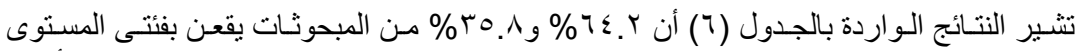

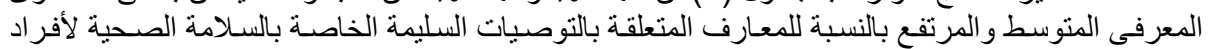

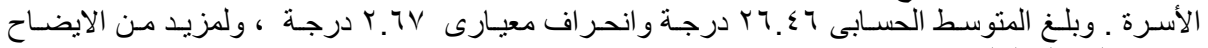

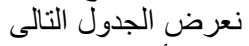

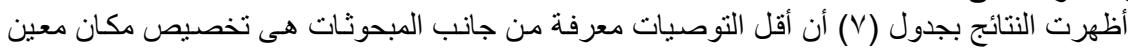

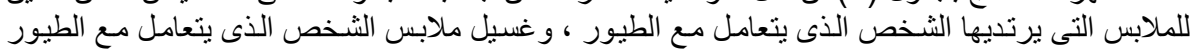

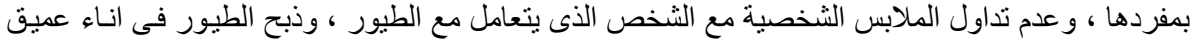

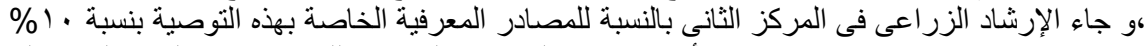

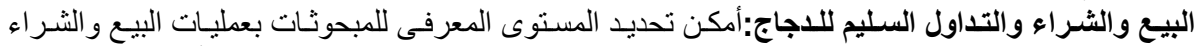

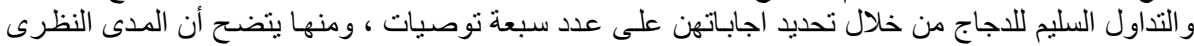

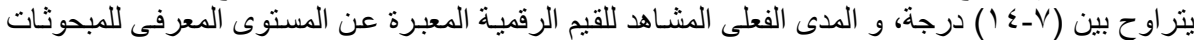

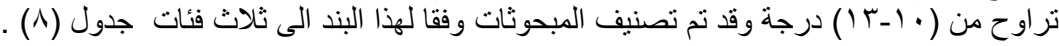

جدول (V): توزيع المبحوثات وفقا لمعارفهن بتوصيات السلامة الصحيه لأفراد الأسرة ومصدر هذه المعرفة

\begin{tabular}{|c|c|c|c|c|c|c|c|c|c|}
\hline \multicolumn{4}{|c|}{ مصدر المعرفة } & \multirow{2}{*}{\multicolumn{2}{|c|}{ لا لا تعرف }} & \multirow{2}{*}{\multicolumn{2}{|c|}{ تعرف }} & \multirow[b]{2}{*}{ البند } & \multirow[b]{2}{*}{ م } \\
\hline \multicolumn{2}{|c|}{ 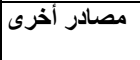 } & \multicolumn{2}{|c|}{ 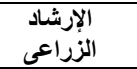 } & & & & & & \\
\hline$\%$ & |العدد & $\%$ & العدد & $\%$ & العدد & $\%$ & |العدد & |ألسلامة الصحيه لأفراد الأسرة & \\
\hline $07 . r$ & $\mathrm{vq}$ & $\varepsilon r . Y$ & 71 & صفر & صفر & $1 \cdots$ & $1 \leqslant 0$ & |بالماء و الصابيلى والأجز اء المكثوفة من الجسم بعد العناية بالطيور & \\
\hline 00 & VV & $\sum 0$ & 4 & صفر & صفر & $1 \cdots$ & $1 \varepsilon \cdot$ & عدم وضع الدو اجن فى غرفة النوم & r \\
\hline$\varepsilon$. & 07 & $r$. & $\varepsilon r$ & $r$ r. & $\varepsilon r$ & $\mathrm{v}$. & 91 & عدم ترك الأو لاد يلعبون مع الدجاج & r \\
\hline 0. & $\mathrm{v} \cdot$ & ro & $\sum 9$ & 10 & YI & 10 & 119 & عدم البقاء مع الكتاكيت أثناء تغذيتها & \\
\hline o. & $\mathrm{v}$. & £o & $\pi$ & o & $\mathrm{v}$ & 90 & IrT & 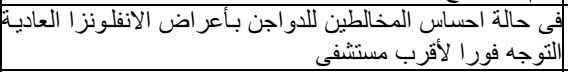 & \\
\hline Tr.r & IV & 1. & $1 \varepsilon$ & VV.A & 1.9 & YY.Y & 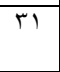 & |عند رعابة ختغذية الطيور (جلباب - حذاء بلاستيك - غطاء للر أس & \\
\hline 0. & $\mathrm{ve}$ & ro & $\sum 9$ & صفر & صفر & $1 \cdots$ & $1 \leqslant$. & لعدم التغذية على اليضض النى مع اللبن & \\
\hline rr.q & Tr & $r$. & rA & $0 \vee .1$ & A. & $\varepsilon r .9$ & 7. & |ارتداء جوانتى فى اليد عند الذبح| & \\
\hline 10 & rI & 1. & $1 \varepsilon$ & vo & 1.0 & ro & ro & |رتداء غطاء على الوجه عند الذبح & \\
\hline 10 & rI & 0 & $\mathrm{v}$ & A. & $11 Y$ & $r \cdot$ & rA & لنجبح الطيور فى اناء عميق & 1. \\
\hline AY.AO & ITr & 15.10 & IV & صفر & صفر & $1 \cdots$ & $1 \varepsilon \cdot$ & |غسيل السكين المستخدم في الذبح مباشرة & 11 \\
\hline $\begin{array}{r}. Y \\
\end{array}$ & 1. & r.o & 0 & $19 .{ }^{\top}$ & Tro & $1 \cdot . \mathrm{V}$ & 10 & غسيل ملابس الثخص الذى يتعامل مع الطيور بمفردها & $\sqrt{17}$ \\
\hline 70 & 91 & ro & $\sum 9$ & صفر & صفر & $1 \cdots$ & $1 \leqslant \cdot$ & |غسيل اليدين بالصابون بعد از الة ريش الطيور & $1 \%$ \\
\hline صفر & |صفر & صفر & صفر & I.. & $1 \leqslant$. & | صفر & صفر & تلخصبص مكان معين للملابس التى يرتديها الثخص الذى يتً & $1 \varepsilon$ \\
\hline
\end{tabular}


J. Agric. Econom. and Social Sci., Mansoura Univ., Vol.3 (2), February, 2012

\begin{tabular}{|c|c|c|c|c|c|c|c|c|}
\hline & & & & & & & & همع الطيور \\
\hline 1. & $1 \varepsilon$ & 0 & $\mathrm{~V}$ & 10 & 119 & 10 & YI & 10 | علدم تداول الملابس الثخصية مـع الثـخص الذى يتعامل مـح \\
\hline Vo. & 1.7 & $r \leqslant . Y$ & $r \varepsilon$ & صفر & صفر & $1 \ldots$ & $1 \leqslant$. & 17 |مكان المعيش مكان للأسرة معين لادوات ومستلزمات الطيور منفصل عن \\
\hline
\end{tabular}

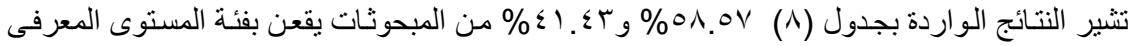

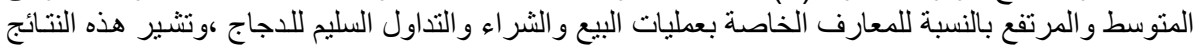

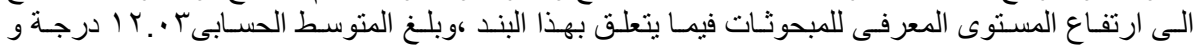

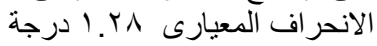

جدول (^): توزيع المبحوثات وفقا لمستوى معارفهن بتوصيات البيع والشراء والتداول السليم للاجاج

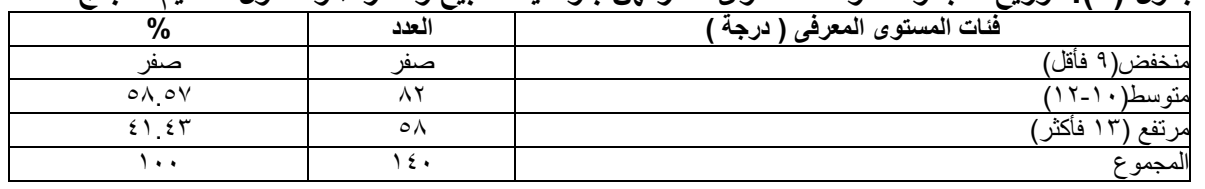

أظهرت النتائج بجدول (9) أن أقل التوصيات معرفة من جانب المبحوثات هى التوصية المتعلقة بغسيل

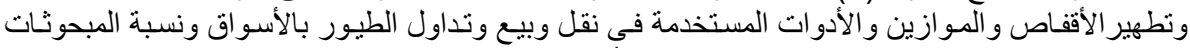

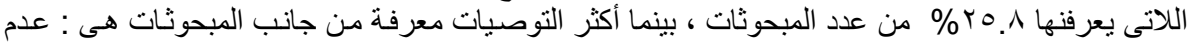

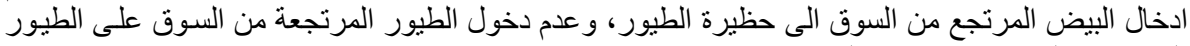

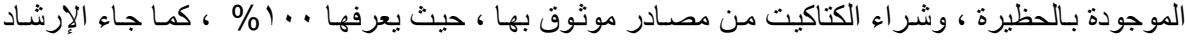

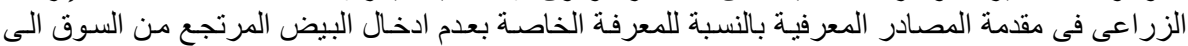

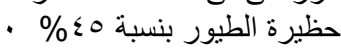

جدول (9): توزيع المبحوثات وفقا لمعارفهن بتوصيات البيع والتداول السليم للاجاج ومصدر هذه المعرفة

\begin{tabular}{|c|c|c|c|c|c|c|c|c|c|}
\hline \multicolumn{4}{|c|}{ مصدر المعرفة } & \multirow{2}{*}{\multicolumn{2}{|c|}{ لا تعرف }} & \multirow{2}{*}{\multicolumn{2}{|c|}{ تعرف }} & \multirow{2}{*}{ البند } & \multirow{3}{*}{. } \\
\hline 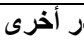 & 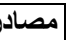 & 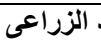 & الإرشا & & & & & & \\
\hline$\%$ & 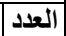 & $\%$ & | العدد & $\%$ & العدد & $\%$ & | العدد & |البيع والشر اء و التداول السلبي للاجاج & \\
\hline Or.r & $\mathrm{VT}$ & $\sum V_{. \wedge}$ & TV & صفر & صفر & 1... & $1 \leqslant$. & | شر اء الكتاكيت من مصادر موثوق بها . & 1 \\
\hline YA. . & $\varepsilon \cdot$ & $17 . \varepsilon$ & $\bar{r}$ & 00 & VV & ¿0 & $\pi$ & شر اء العلائق من مصادر موثوق بها. & r \\
\hline $10 . \mathrm{V}$ & rr & 1. & $1 \varepsilon$ & $V \leqslant . r$ & $1 \cdot \varepsilon$ & ro.A & r4 & 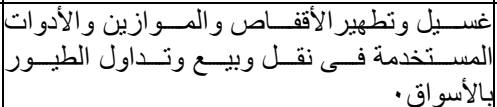 & $r$ \\
\hline $00 . \mathrm{V}$ & VN & $\varepsilon \leqslant . \Gamma$ & $T Y$ & صفر & صفر & $1 \ldots$ & $1 \leqslant \cdot k$ & 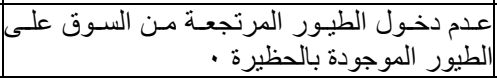 & $\varepsilon$ \\
\hline 00 & $\mathrm{~V} V$ & $\leqslant 0$ & $\pi$ & صفر & صفر & $1 \ldots$ & $1 \leqslant 0$ & 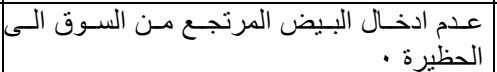 & 0 \\
\hline TY.N & $\leqslant 7$ & $r \cdot$ & $\varepsilon r$ & rV. 10 & $O r$ & $7 r .10$ & $\Lambda N$ & شر اء بيض الفقس من مصادر موثوق بها. & 7 \\
\hline$\varepsilon$. & 07 & $r$. & $\varepsilon r$ & r. & $\leqslant r$ & $V \cdot$ & 91 & أن تكون هناك أدوات مخصصة لجمع البيض & $\mathrm{v}$ \\
\hline
\end{tabular}

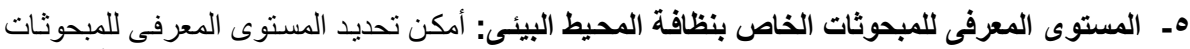

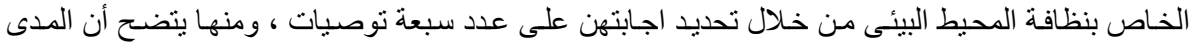

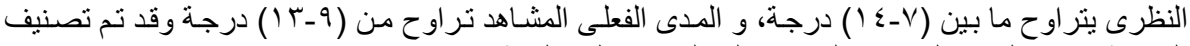

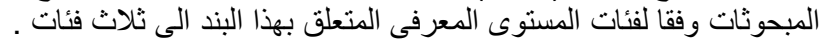


El-Zarka, Z. M. et al.

جدول ( • 1) توزيع المبحوثات وفقا لمستوى معارفهن بتوصيات نظافة المحيط البيئى

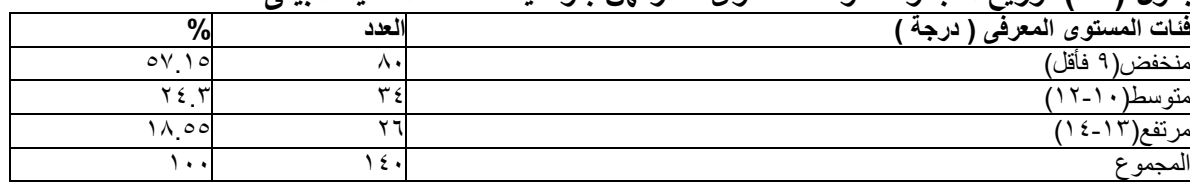

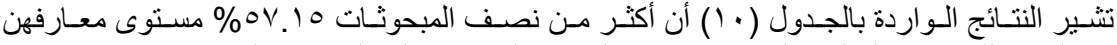

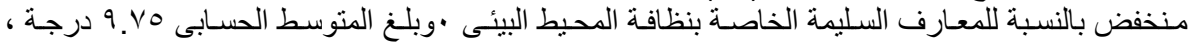

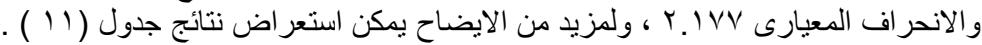

جدول (1') توزيع المبحوثات وفقا لمعارفهن بتوصيات نظافة المحيط البيئى ومصدر هذه المعرفة

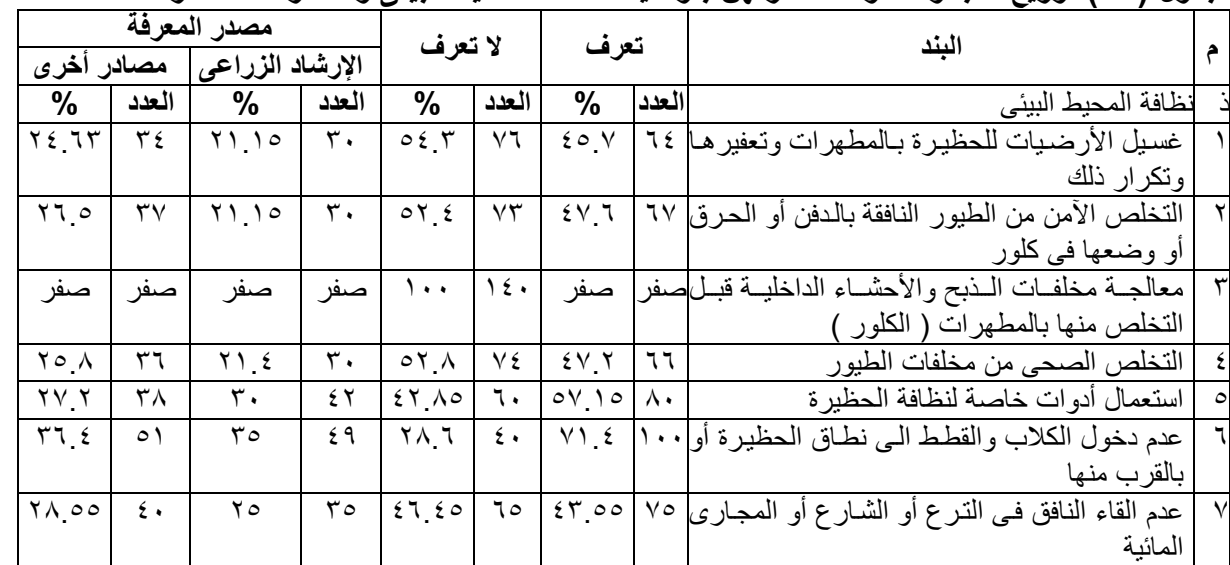

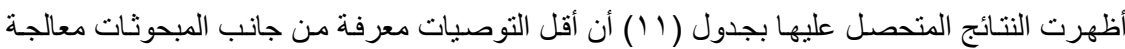

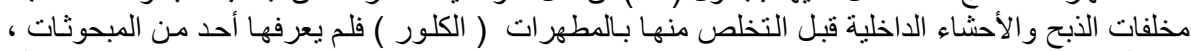

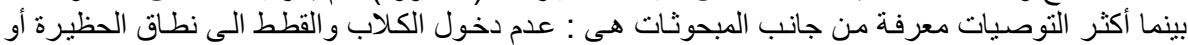

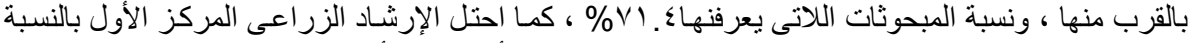

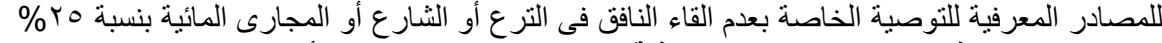

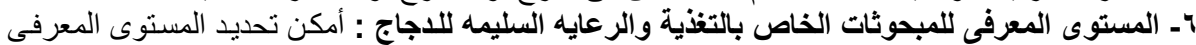

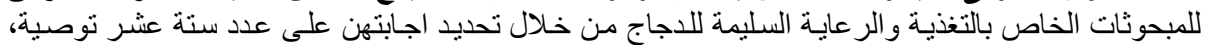

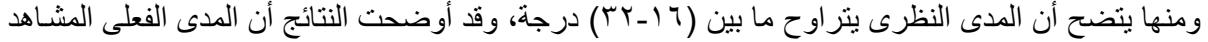

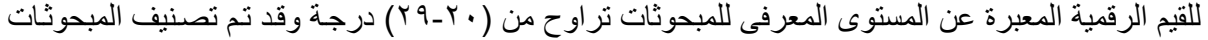

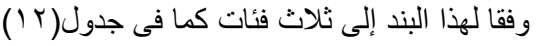

جدول (r ا ) توزيع المبحوثات وفقا لمستوى معارفهن بتوصيات التغذية والرعايه السليمة للاجاج

\begin{tabular}{|c|c|c|}
\hline$\%$ & 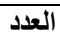 & فئات المستوى المعرفى ( درجة ) \\
\hline$r \cdot . \Lambda$ & $\varepsilon r$ & منخفض( ال فأقلّ) \\
\hline $1 \leqslant . Y$ & T. & متو سط (YV_YY) \\
\hline 00 & VV & مرتفع (ر) فأكثر ) \\
\hline $1 \ldots$ & $1 \leqslant$. & المجموع \\
\hline
\end{tabular}

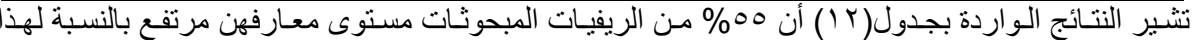

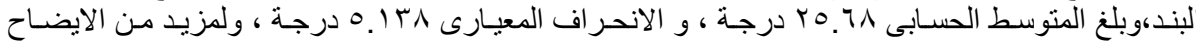

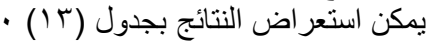


J. Agric. Econom. and Social Sci., Mansoura Univ., Vol.3 (2), February, 2012

جدول (ب ا ) توزيع المبحوثات وفقا لمعارفهن بتوصيات التغذية والرعايـة السليمة للاجاج ومصدر هذه

\begin{tabular}{|c|c|c|c|c|c|c|c|c|c|}
\hline & & & & & & & & & \\
\hline & 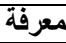 & مصدر | مصر & & & & & & & \\
\hline أخرى & 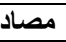 & 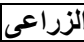 & 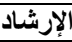 & & & & & آبج & ? \\
\hline$\%$ & 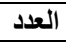 & $\%$ & 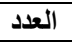 & $\%$ & 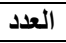 & $\%$ & ا لعدد & |التخذية والرعايه السليمه للاجاج & 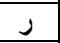 \\
\hline rq. & $\varepsilon 1$ & ro & «9 & ro.1 & 0. & $7 \varepsilon . Y$ & 9. & تخصيص أماكن مناسبة لتخزين الأعلاف & 1 \\
\hline ro & $\$ 9$ & rq. & \&1 & ro.A & 0 . & $T \Sigma . Y$ & 9. & 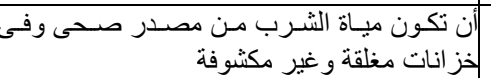 & $r$ \\
\hline 7. & $\Lambda \varepsilon$ & $\xi$. & 07 & صفر & صفر & $1 \cdots$ & $1 \varepsilon \cdot$ & |النظافة الجيدة لأدوات التغذية والشرب. & $r$ \\
\hline$\varepsilon \varepsilon . Y$ & Tr & To & ro & $r \cdot . \wedge$ & $\varepsilon r$ & 79.4 & $9 \mathrm{~V}$ & 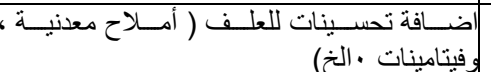 & $\varepsilon$ \\
\hline ro & $\leqslant 9$ & $r \cdot$ & rA & $\varepsilon 0$ & $\pi$ & 00 & VV & |الحرص على تربية السلالات المستحدثة & $\circ$ \\
\hline r..0 & rv & $r \leqslant . r$ & $r \varepsilon$ & $\sum 9 . r$ & 79 & $0 . .1$ & vi & فُرش الأرضية(تبن،نشارة خشب،قش أرز) & 1 \\
\hline Tr.I & $\leqslant 0$ & YO.Y & rq & $\sum Y . Y$ & 09 & $0 \vee .1$ & AI & |الحرص على تجديد القطيع & $\mathrm{v}$ \\
\hline 1. & $1 \leqslant$ & $\circ$ & $\mathrm{V}$ & 10 & 119 & 10 & YI & نوفير بياضات للطيور البياضة & $\Lambda$ \\
\hline$r \cdot$ & $\sum Y$ & $10 . \mathrm{V}$ & TY & 00 & VV & $\leqslant 0$ & $\pi$ & لتوفير دفاية جاز & 9 \\
\hline 1. & $1 \leq$ & $\varepsilon . Y$ & 7 & 10.1 & Ir. & $1 \leq . Y$ & r. & |ضافة الجير المطفى للتطهير & 1. \\
\hline$r .7$ & $\varepsilon \varepsilon$ & rV.I & rA & «1. & 01 & $0 \wedge . V$ & $\lambda r$ & ضبط درجة الحرارة & 11 \\
\hline$\varepsilon \cdot$ & 07 & ro & $\sum 9$ & ro & ro & vo & 1.0 & لتهحات التهوية أعلى من مستوى الطيور & Ir \\
\hline 0. & $\mathrm{~V}$. & ro & $\leqslant 9$ & 10 & Y & 10 & 119 & تغيير الفرشة & $1 \pi$ \\
\hline$\varepsilon Y . q$ & 7. & $\varepsilon r .1$ & 09 & 10 & $r$ & 10 & 119 & تغيير الفرشة بصفة دورية & $1 \leq$ \\
\hline$v \cdot$ & 91 & $r$. & $\sum r$ & صفر & صفر & $1 \cdots$ & $1 \leqslant \cdot$ & توفير اضاءة لمكان التربية & 10 \\
\hline IV.V & $r \varepsilon$ & 11.0 & IV & $\vee \cdot . \wedge$ & 99 & YQ. & « & التحصين بصفة دورية & 17 \\
\hline
\end{tabular}

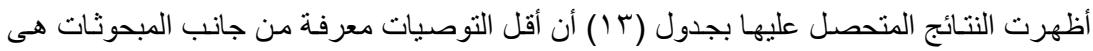

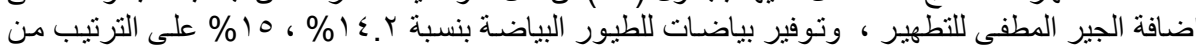

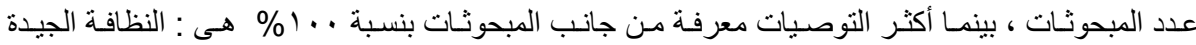

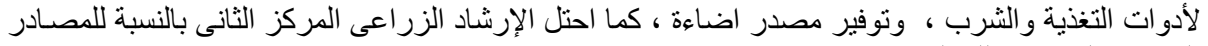

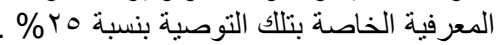

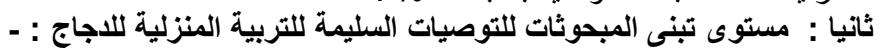

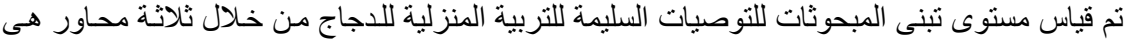

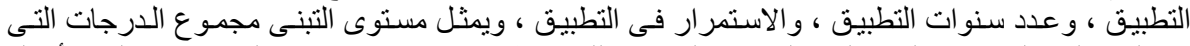

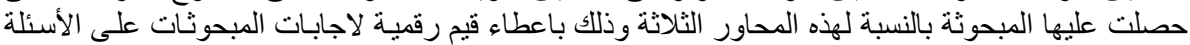

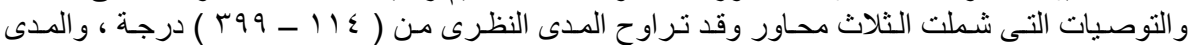

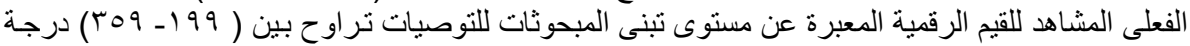
وقد تم تصنيف المبحوثات وفقا لمستوى تبنيهم للتوصيات السليمة للتربية المنزلية للاجباج الى ثنلاث مستويات

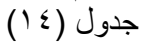

جدول (؛ () توزيع المبحوثات وفقا لمستوى تبنيهن للتوصيات السليمة للتربية المنزلية للاجاج

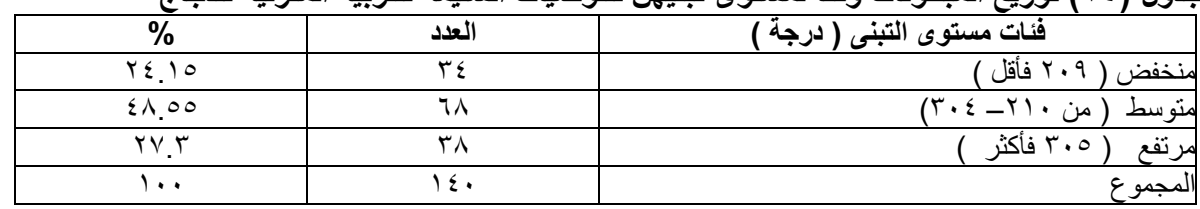

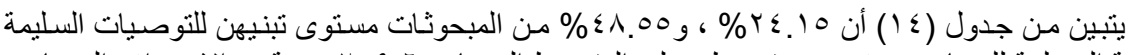

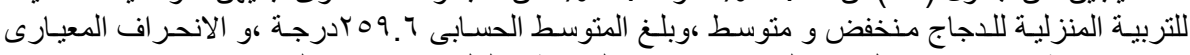

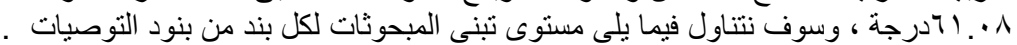


El-Zarka, Z. M. et al.

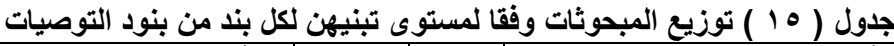

\begin{tabular}{|c|c|c|c|c|c|}
\hline$\%$ & عدد & فُئات مستوى التبنى لبنود التوصيات & $\%$ & عدد & فئات مستوى التبنى لبنود التوصيات \\
\hline & & ع ـ نظافة المحيط البيئى & & & | -احتياطات الوقاية والتربية المنزلية \\
\hline$\vee 9.7$ & 111 & منخفض ( ب أفقل ) & ro & ro & منخفض ( •ـ فأقل) \\
\hline Ir.A & 11 & متوسط (YN-YY ) & 79.40 & 9. & متوسط (إ_ـ9 (09) \\
\hline$V . \Lambda$ & 11 & مرتفع ( qَس فأكثر ) & $1 . .20$ & 10 & مرتفع ( •ج فأكثر) \\
\hline & & هـ التغذية والرعاية السليمة للاجاج & & & |r-السلامة الصحية لأفراد الأسرة \\
\hline ro & $\leqslant 9$ & منخفض ( 9 ه فأقل ) & صفر & صفر & لمنخفض (9 هأقل) \\
\hline r. & so & 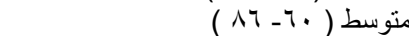 & $T V . \Lambda$ & 90 & 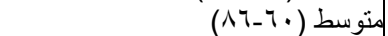 \\
\hline \multirow[t]{5}{*}{ r. $q$} & $\leq 7$ & مرتفع ( NV فأكثر ) & MT.r & $\leqslant 0$ & مرتفع (NV فأكثر) \\
\hline & & & & & |r-البيع والثراعوالتداول السليم \\
\hline & & & 17.0 & rt & منخفض (T Y فأقل) \\
\hline & & & $\varepsilon \cdot . V$ & ov & متوسط (YN-rV) \\
\hline & & & $\sum r . \wedge$ & 7. & مرتفع (q ب فأكثر) \\
\hline
\end{tabular}

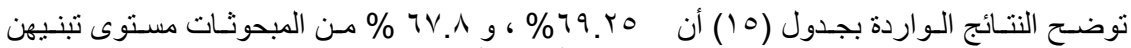

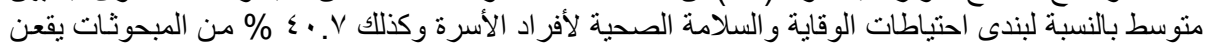

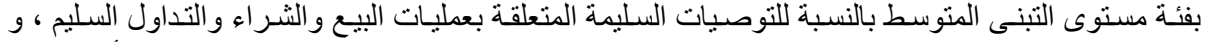

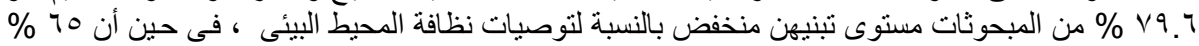

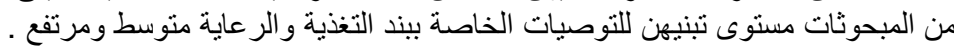

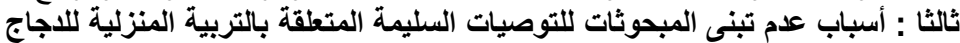

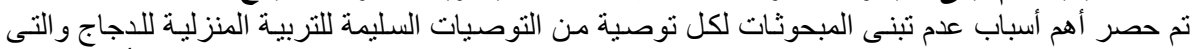

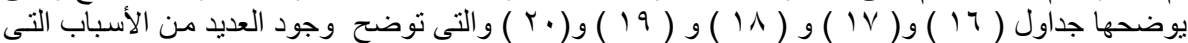

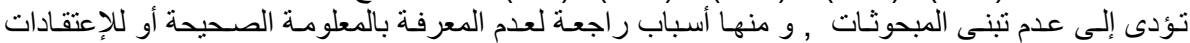
الخاطئة أو لعادات وتقاليد خاطئة أو لعدم توفر امكانيات التطبيق .

جدول (7 (1): أسباب عدم تبنى التوصيات السليمة لاحتياطات الوقاية والتربية المنزلية الصحية للاجاج

\begin{tabular}{|c|c|c|c|c|c|}
\hline$\%$ & التكرار & أسباب عدم التبنى & \begin{tabular}{|c|}
$\%$ \\
\\
التبنى \\
\end{tabular} & التوصيات & \\
\hline $\begin{array}{l}1.00 \\
1.10 \\
1.00\end{array}$ & $\begin{array}{c}\dot{r} \\
\dot{r}\end{array}$ & 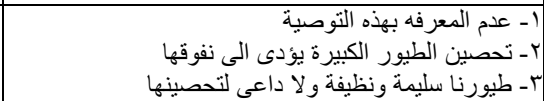 & vo & تحصين الطيور & 1 \\
\hline $\begin{array}{l}0.10 \\
\text { NV.10 }\end{array}$ & IKr & 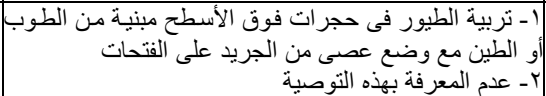 & 94.9 & 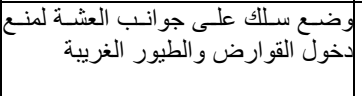 & $r$ \\
\hline $\begin{array}{l}V V .10 \\
r .10\end{array}$ & $\begin{array}{c}1 \cdot 1 \\
\varepsilon\end{array}$ & |r - ضدم المعرفة بهذه التوصية للتربية & $\wedge$. & تربية كل نوع من الطيور على حدة & $r$ \\
\hline $\begin{array}{l}\text { r. } \\
\text { vo. }\end{array}$ & $\begin{array}{l}0 \\
1.7\end{array}$ & ץ- - عدرورة المعرفة بهذه الطيور تتحرك بحرية & V9.1 & الامتناع عن تربية الطيور فى العراء & $\varepsilon$ \\
\hline r. & $\begin{array}{l}\varepsilon r \\
11\end{array}$ & 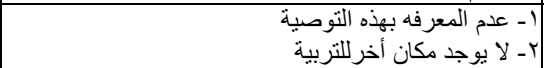 & rv. & 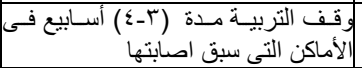 & 0 \\
\hline १. & $\begin{array}{c}07 \\
9\end{array}$ & |r | - علفم المعرفة بهذه التوصيه & $\{7 . \leqslant$ & |تتربية الطيور فى عشش مسقوفة وجيدة & 7 \\
\hline $\begin{array}{l}\sum \Lambda .00 \\
V . Y\end{array}$ & $\begin{array}{ll}71 \\
1 .\end{array}$ & | - - عدم المعرفة بهذه التويه من الصيدليه البيطرية & 00.12 & 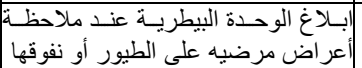 & $\mathrm{v}$ \\
\hline $\begin{array}{l}2 r .70 \\
1 Y .10\end{array}$ & $\begin{array}{ll}71 \\
\text { IV }\end{array}$ & 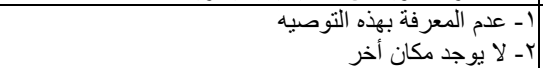 & 00.1 & 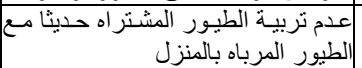 & $\hat{\lambda}$ \\
\hline $\begin{array}{ll}r \cdot r \\
\varepsilon \cdot r\end{array}$ & $\begin{array}{c}r \wedge \\
1\end{array}$ & 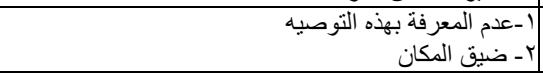 & $r \leqslant . Y$ & التشميس الجيد للحظائر و العشش & 9 \\
\hline i. & $\begin{array}{l}1 \leqslant \\
115\end{array}$ & |r |- ضديق المكرفة بهذه التوصيه & 19.5 & وضعيشة العشة فى مكان منفصل عن مكان & 1. \\
\hline
\end{tabular}

جدول (IV): أسباب عدم تبنى التوصيات السليمة للسلامة الصحية لأفراد الأسرة 
J. Agric. Econom. and Social Sci., Mansoura Univ., Vol.3 (2), February, 2012

\begin{tabular}{|c|c|c|c|c|c|}
\hline$\%$ & التكرار & أسباب عدم التبنى & 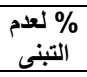 & التوصيات & s \\
\hline $\begin{array}{c}\text { r. } \\
\text { r. }\end{array}$ & 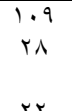 & 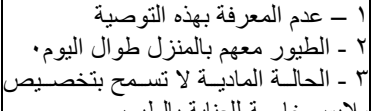 & 97.5 & 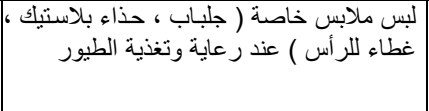 & 1 \\
\hline $10 . \mathrm{V}$ & rr & ملابس خاصة للعناية بالطيور & & & \\
\hline $\begin{array}{l}\text { a.t } \\
\text { Or. } \\
r .0\end{array}$ & 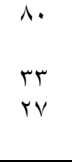 & 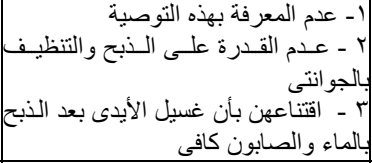 & $1 \cdots$ & جوانتى عند الذبح & $T$ \\
\hline $\begin{array}{l}19 . \mathrm{r} \\
1 \cdot . \mathrm{V}\end{array}$ & $\begin{array}{l}1 \% 0 \\
10\end{array}$ & 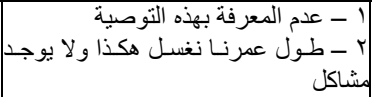 & $1 \cdots$ & 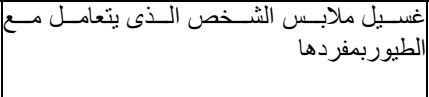 & $r$ \\
\hline $\begin{array}{l}\text { A. } \\
r .\end{array}$ & $\begin{array}{l}114 \\
4 \mu\end{array}$ & 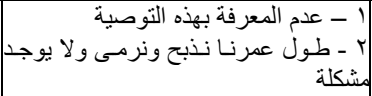 & $1 \cdots$ & النبح الطيور فى اناء عميق & $\varepsilon$ \\
\hline $\begin{array}{l}10 \\
10\end{array}$ & $\begin{array}{l}119 \\
11\end{array}$ & \begin{tabular}{|l}
$\mid$ \\
\end{tabular} & $1 \cdots$ & بتعامل مع الطيور الملابس الشخصية مع الثخص الذى & 0 \\
\hline $\begin{array}{ll}1 \cdots \\
0 \leqslant . r\end{array}$ & $\begin{array}{ll}1 \varepsilon \cdot \\
V 4\end{array}$ & 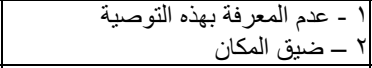 & $1 \cdots$ & 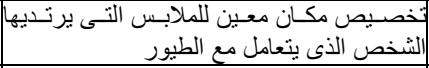 & 7 \\
\hline $\begin{array}{ll}\text { Vo } \\
r \cdot . V\end{array}$ & $\begin{array}{l}1.0 \\
10\end{array}$ & \begin{tabular}{r|}
$\mid$ \\
\end{tabular} & $1 \cdots$ & |ر منداء غطاء على الوجة عند الذبح مثل الطرحسة & $\mathrm{v}$ \\
\hline $\begin{array}{l}10 \\
r \Lambda . V\end{array}$ & r) & |r-حتى نتابع الكتاكيت المعرفة بهزية & $\varepsilon r . V$ & عدم البقاء مع الكتاكيت أثناء تغذيتها & 人 \\
\hline $\begin{array}{ll}r \\
r \cdot \lambda\end{array}$ & $\begin{array}{cl}\varepsilon Y \\
1\end{array}$ & |r |- ال داعم المعرفة بهذه التوصية & $r \cdot . \Lambda$ & عدم ترك الأو لاد يلعبون مع الدجاج & 9 \\
\hline 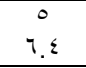 & $\begin{array}{l} \\
q \\
\end{array}$ & |r إ- نتوجه المعرفة بهذه التوصية الصية البشرية & $11 . \varepsilon$ & 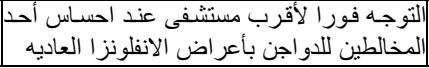 & 1. \\
\hline
\end{tabular}

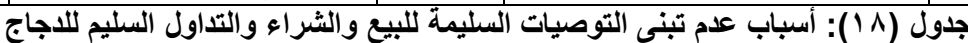

\begin{tabular}{|c|c|c|c|c|c|}
\hline$\%$ & 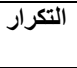 & |أسباب عدم التبنى & 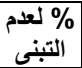 & |التوصية & \\
\hline $19 . \varepsilon$ & TV & | - إيق الوقت & AT.T & 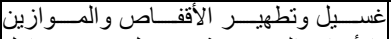 & 1 \\
\hline rᄉ.o & $\varepsilon$. & r ـ الخوف عليها من الرطوبة & & [ الأدو ات المستخدمة فى نقل وبيع وتداول] & \\
\hline$V \leqslant . Y_{0}$ & $1 \cdot \varepsilon$ & |- عدم المعرفة بهذه التوصية & & | الطيور بالأسو اق & \\
\hline 00 & $V V$ & | - عدم المعرفة بهذه التوصية & $7 \cdot .1$ & شُ شر اء العلائق من مصادر موثوق بها & $Y$ \\
\hline 0.1 & $\wedge$ & r ب- يتغذو ا على بقايا المنزل من الحبوب & & & \\
\hline r.. & or & | |- عدم المعرفة بهذه التوصية & or. 7 & الفقس من مصادر موثوق بها & 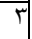 \\
\hline 17.0 & rt & r - بيض الفقس يوجد لدينا ومصدره طيورنا & & & \\
\hline r. & $\varepsilon r$ & | |- عدم المعرفة بهذه التوصية & ry. & البــــ ومكــان & $\varepsilon$ \\
\hline $7 . \varepsilon$ & 9 & بـ البيض لا يمثل لنا مشكلة & & لتجميعه & \\
\hline rY.q & rt & الكتاكيت مصدر ها التفريخ فى المنزل & YY.9 & شر اء الكتاكيت من مصادر موثوق بها & $\circ$ \\
\hline $1 . Y$ & r & ان تحدث مشاكل لدينا من جر اء ذللك & I.Y & لحظيرة الدال الطيور المرتجعة من السوق الىى & 7 \\
\hline
\end{tabular}

\begin{tabular}{|c|c|c|c|c|c|}
\hline$\%$ & التكرار & | اسبباب عدم التبنى | & \% التبنى لعدم & التوصيات & \\
\hline 10 & YI & ا ترمى فى المصرف أسهل & 10 & التخلص الصحى من مخلفات الطيور ( سبلة & 1 \\
\hline or.A & $V \varepsilon$ & r عدم المعرفة بهذه ا لتوصية & & 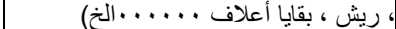 & \\
\hline IV.r & $r \leqslant$ & ب ب ترمى على السماد البلدى ب ب & & & \\
\hline$r \cdot$ & rᄉ & | - لا يوجد مكان أخر للتخلص منها & NY.r & عـدم القـاء النـافق فـى التـرع أو الثـار ع أو & $\varphi$ \\
\hline$\leqslant 7 . \leqslant 0$ & 70 & |r- عدم المعرفة بهذه التوصية & & المجارى المائية & \\
\hline 10.10 & rt & ا ب - اعنادنا على ذلك & & & \\
\hline ro & «9 & | - ترمى للكلاب و القطط لتتغذى عليها & AV.Y & التخلص الآمن من الطيور النافقة & $\varphi$ \\
\hline or.r & $\mathrm{vr}$ & | r- عدم المعرفة بهذه التوصية & & & \\
\hline YI. $\leqslant 0$ & re. & | - مكلفة و الحالة المادية لا تسمح & $9 V . Y$ & غســل الأرضـيات للحظيـرة بــالمطهر ات & $\xi$ \\
\hline $0 \leqslant . r$ & Vy & Y-عدم المعرفة بهذه التوصية & & وتتعفير ها وتكر ار ذلك & \\
\hline
\end{tabular}

195 
El-Zarka, Z. M. et al.

\begin{tabular}{|c|c|c|c|c|c|}
\hline YI. $\leqslant 0$ & $r \cdot$ & |ب- الأرضية تر اب وننظفها كل يوم & & & \\
\hline 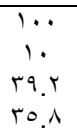 & $\begin{array}{l}1 \leqslant \\
1 \leqslant \\
00 \\
0 .\end{array}$ & 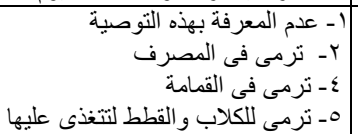 & $\cdots$ & التخلص منها مخلفات الذبح و الأحشاء الداخلية قبل & 0 \\
\hline $\begin{array}{l}\sum Y .10 \\
1 V .10\end{array}$ & $\begin{array}{l}T \\
T \leq\end{array}$ & |r - مكلفم المعرفة بهذه التوصية & 7. & |استعمال أدوات خاصة لنظافة الحظيرة & 7 \\
\hline $\begin{array}{l}r \wedge .7 \\
\vee .9\end{array}$ & $\begin{array}{ll}\varepsilon \\
11\end{array}$ & | ب- الحظيرة المعرفة بهذه التوصية & r..0 & 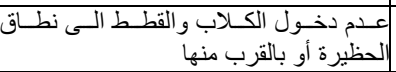 & $\mathrm{v}$ \\
\hline
\end{tabular}

رابعا : الإرتباطات وتحليل الإتحدار المتعدد المتدرج الصاعد :

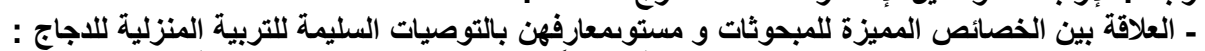

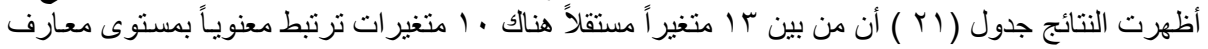

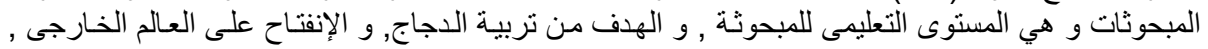

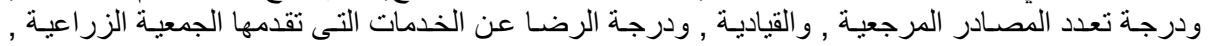

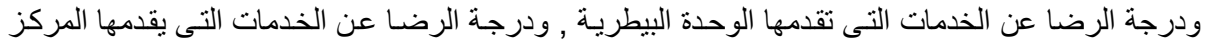

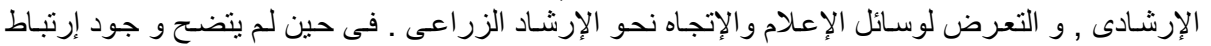
معنوى بين معارف المبحوثات , و سن المبحوثة , و المستوى التعليمى للزوج ، الإن ، والحيازة الداجنية.

\begin{tabular}{|c|c|c|c|c|c|}
\hline$\%$ & 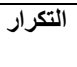 & 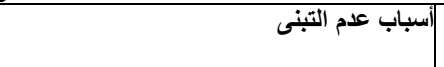 & 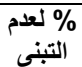 & |التوصيات & \\
\hline TY. & $\sum 0$ & ا العشة درجة حر ارتها مناسبة و لا توجد مشكلة & $V T .7$ & ضبط درجة الحرارة & \\
\hline$\leqslant 1 . \varepsilon$ & $0 \wedge$ & Y عدم المعرفة بهذه التوصية & & & \\
\hline 7. & $\Lambda \varepsilon$ & ا لا توجد فرشة & vo & تغيير لفرشة & r \\
\hline 10 & rI & r عدم المعرفة بهذه التوصية & & & \\
\hline$V \cdot . \wedge$ & 99 & 1 ا عدم المعرفة بهذه التوصية & Vo & |التحصين بصفة دورية & $r$ \\
\hline 19.1 & TV & |r-اقتناعهن بأنة ليس هناك ضرورة لذلك & & & \\
\hline $10 . \mathrm{V}$ & rt & | - - مكلفة & & & \\
\hline VY. 9 & $1 \cdot r$ & | - إ مكلفة & AV. 9 & تغيير الفرشة بصفة دورية & $\varepsilon$ \\
\hline 10 & r) & |r-عدم المعرفة بهذه التوصية & & & \\
\hline 00 & $V V$ & | |-عدم المعرفة بهذه التوصية & $94 . \wedge$ & توفير دفاية غاز & 0 \\
\hline ri.0 & r. & r - جو العشة مناسب و معتدل & & & \\
\hline $1 v .1$ & $r \leq$ & 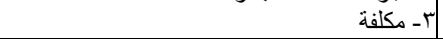 & & & \\
\hline 10 & 119 & | |- عدم المعرفة بهذه التوصية & 90 & توفير بياضات للطيور البياضة & 기 \\
\hline ro. $\mathrm{V}$ & $\circ$. & |r- الطيور تبيض فى العشة ولسنا فى حاحة لذلك & & & \\
\hline 1०.人 & Tr. & | |- عدم المعرفة بهذه التوصية & $1 \cdots$ & |ضافة الجير المطفى للتطهير & 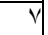 \\
\hline $1 \leq .4$ & r. & 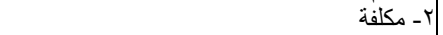 & & & \\
\hline$\sum 9.1$ & 79 & || عدم المعرفة بهذه التوصية & 00.1 & فـرش الأرضسية ( تـبن & $\lambda$ \\
\hline 7.7 & 9 & 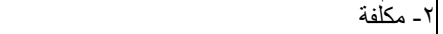 & & خشب ، قش أرز & \\
\hline$\leqslant 0$ & Tr & | |- عدم المعرفة بهذه التوصية & or.7 & |الحـرص علـى تربيـة السـلالات & 9 \\
\hline 1. 7 & ir & r ا ب مكلفة & & |المستحدثه & \\
\hline ro.1 & 0. & | |- عدم المعرفة بهذه التوصبة & or.7 & تخصيص أمساكن مناسبه لتخزين & $1 \cdot$ \\
\hline IV.A & ro & | ب- ضيق المكان & & 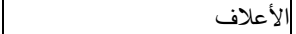 & \\
\hline ro.1 & 0. & || عدم المعرفة بهذه التوصية & 0.11 & ميـاه الثـرب من مصـدر صـحى & 11 \\
\hline 10 & Y & | ب قلة الإمكانيات المادية & & مكثشوفي خز انــات مغلقـــه وغيــر & \\
\hline$\varepsilon Y . Y$ & 09 & || عدم المعرفة بهذه التوصية & $\sum 9.4$ & الحــرص علــى تجديــد القطيــح & $1 Y$ \\
\hline$v$ & 1. & |r لـ لن نضمن الجديد & & للمحافظ & \\
\hline & & & & |الإقتصادى & \\
\hline$r \cdot . V$ & $\varepsilon r$ & | |- عدم المعرفة بهذه التوصية & $\sum Y . \wedge 0$ & |اضـافة تحسينات للعلف ( أمـلاح & 14 \\
\hline $1 T .10$ & iv & | - - - مكلفة & & معدنيـة ،فيتامينـات . . . . . . . . & \\
\hline
\end{tabular}


J. Agric. Econom. and Social Sci., Mansoura Univ., Vol.3 (2), February, 2012

\begin{tabular}{|c|c|c|c|c|}
\hline & & & & | \\
\hline TO & ro & 1- عدم المعرفة بهذه التوصية & $\varepsilon \cdot$ & فتحات التهوية أعلى من مستوى \\
\hline 10 & r) & r- لا يو جد مشكلة فى التهوية & & |الطيو \\
\hline
\end{tabular}

جدول ( ا Y): قيم معامل الإرتبـاط البسيط بين المتغيرات المستقلة المدروسـة و مستوى معرفة المبحوثات

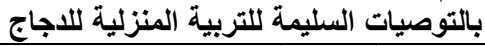

\begin{tabular}{|c|c|c|}
\hline قيم معامل الارتباط البسيط & |المتغيرات المستقلة المدروسة & \\
\hline-0.123 & سن المبحوثة & 1 \\
\hline${ }^{* *} 0.562$ & | المستوى التعليمى للمبحوثة & $Y$ \\
\hline 0.023 & | المستوى التعليمى للزوج & $r$ \\
\hline 0.048 & |الحيازة الداجنية للأسرة & $\varepsilon$ \\
\hline${ }^{\star *} 0.474$ & | الهدف من التربية & 5 \\
\hline${ }^{* *} 0.463$ & |الانفتاح على العالم الخارجى & 6 \\
\hline$* .190$ & لـرجة تعدد المصادر المرجعية & 7 \\
\hline${ }^{* *} 0.313$ & | القبادية & 8 \\
\hline${ }^{\star} 0.172$ & |درجة الرضا عن الخدمات التى تقدمها الجمعية الزر اعبة & 9 \\
\hline${ }^{* *} 0.424$ & لـرجة الرضا عن الخدمات التى تقدمها الوحدة البيطرية & 1. \\
\hline${ }^{\star *} 0.503$ & لَرجة الرضا عن الخدمات التى يقدمها المركز الإرشادى & 11 \\
\hline${ }^{\star *} 0.437$ & |ألتعرض لوسائل الإعلام & TY \\
\hline${ }^{* *} 0.543$ & لـرجة الإتجاة نحو الإرشاد الزراعى & 14 \\
\hline
\end{tabular}

العلاقة بين الذصائص المميزة للمبحوثات و مستوى تبنيهن للتوصيات السليمة للتربية المنزلية للاجاج:

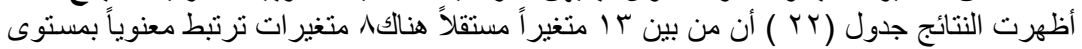

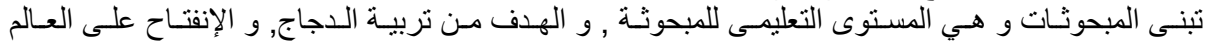

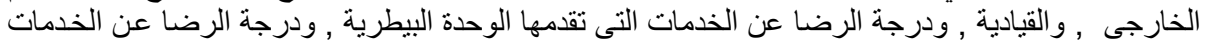

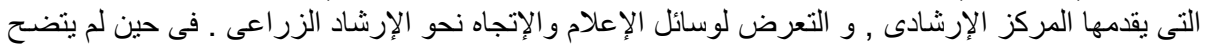

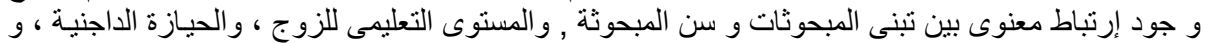

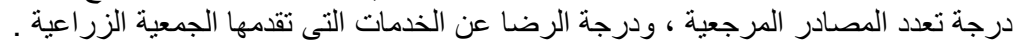

جدول (Yr): قيم معامل الإرتباط البسيط بين المتغيرات المستقلة المدروسة وبين مستوى تبنى المبحوثات

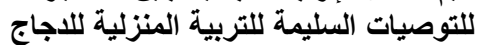

\begin{tabular}{|c|c|c|}
\hline معامل الارتباط البسيط & |المتغيرات المستقلة & $\theta$ \\
\hline-0.047 & لمن المبحوثة & 1 \\
\hline ** 0.459 & |المستوى التعليمى للمبحوثة & $Y$ \\
\hline 0.033 & | المستوى التعليمى للزوج & $r$ \\
\hline-0.033 & حيازة الأسرة من الدجاج & $\xi$ \\
\hline${ }^{\star *} 0.346$ & | الهدف من التربية & 5 \\
\hline${ }^{\star *} 0.372$ & |لانفتاح على العالم الخارجى & 6 \\
\hline 0.161 & لـرجة تعدد المصادر المرجعية & 7 \\
\hline${ }^{* *} 0.266$ & |القيادية & 8 \\
\hline 0.137 & |درجة الرضا عن الخدمات التى تقدمها الجمعية الزراعية & 9 \\
\hline${ }^{* \star} 0.373$ & لدرجة الرضا عن الخدمات التى تقدمها الوحدة البيطرية & 1. \\
\hline${ }^{* *} 0.412$ & لدرجة الرضا عن الخدمات التى يقدمها المركز الإرشادى & 11 \\
\hline${ }^{\star *} 0.362$ & |التتعرض لوسائل الإعلام & TY \\
\hline${ }^{\star *} 0.421$ & |-درجة الإتجاة نحو الإرشاد الزراعى & 13 \\
\hline
\end{tabular}

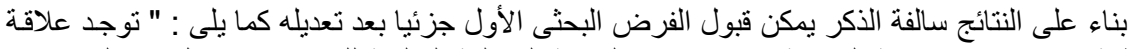

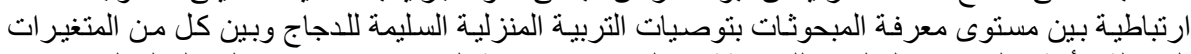

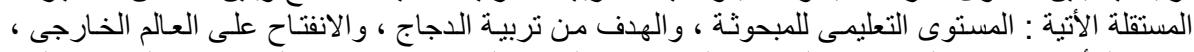

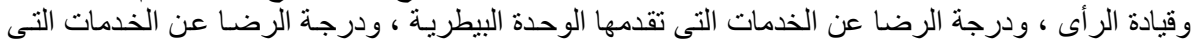


El-Zarka, Z. M. et al.

يقدمها المركز الإرشادى ، والتعرض لوسائل الإعلام ، ودرجة الاتجاه نحو الإرشاد الزر اعى ، ودرجة تعدد

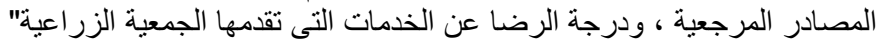

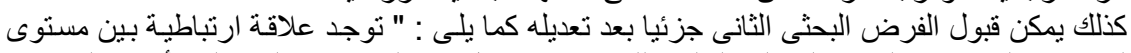

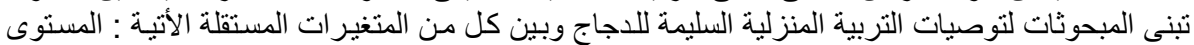

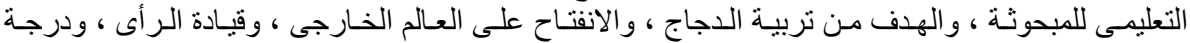

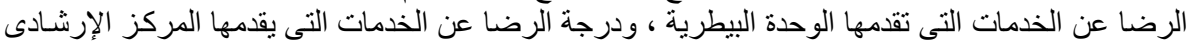

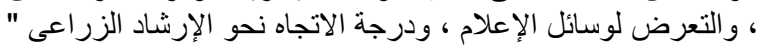

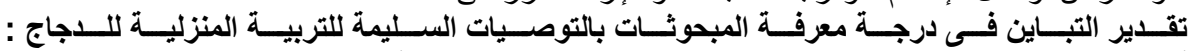

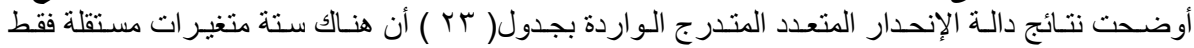

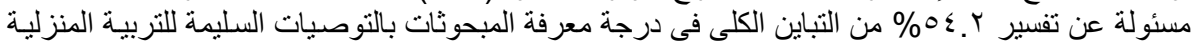

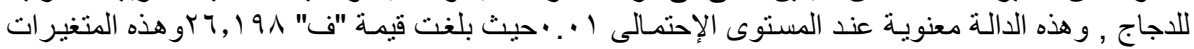

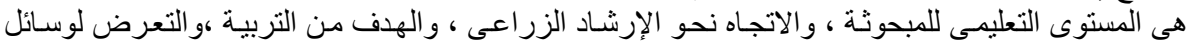

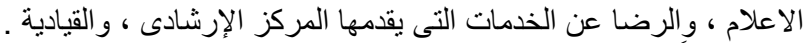

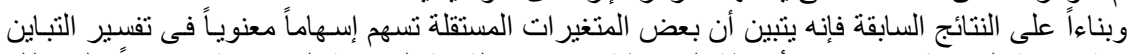

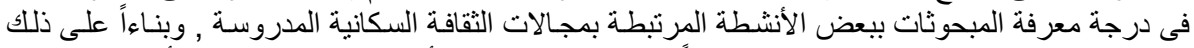

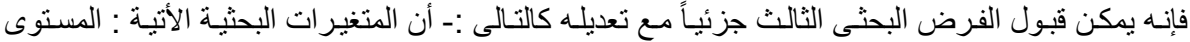

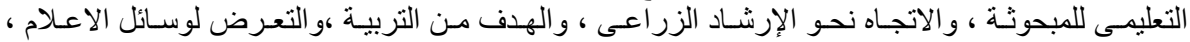

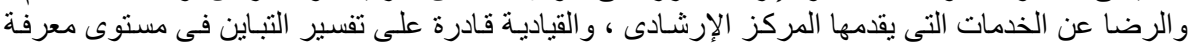

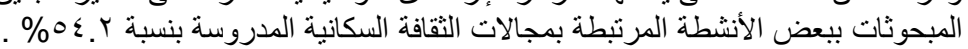

جدول (rr): التحليل الارتباطى والانحارى المتعدد المراحل لعلاقة المستوى المعرفى للمبحوثات بالمتغيرات

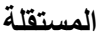

\begin{tabular}{|c|c|c|c|c|c|}
\hline لإختبار معنوية المحسبة & \% ل للتباين المفسر & 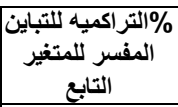 & معامل الإرتباط المتعدد & المتغير الداخل فى التحليل & b \\
\hline \multirow[t]{6}{*}{26.198} & 31.6 & 31.6 & 0.245 & المستوى التعليمى للمبحوثه & 1 \\
\hline & 11 & 42.6 & 0.256 & الإتجاه نحو الإرشاد الزراعى & $r$ \\
\hline & 3.5 & 46.1 & 0.206 & |لهدف من التربية & $r$ \\
\hline & 4 & 50.1 & 0.187 & |التتعرض لوسائل الإعلام & $\varepsilon$ \\
\hline & 1.9 & 52.0 & 0.212 & الإرشادى عن الخدمات التى يقدمها المركز & 0 \\
\hline & 2.2 & 54.2 & 0.169 & |القيادية & \\
\hline
\end{tabular}

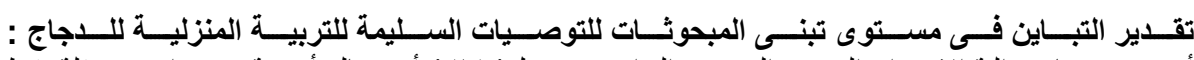

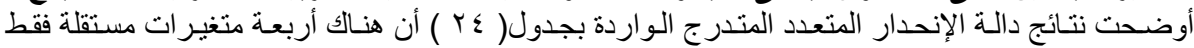

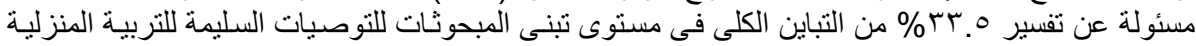

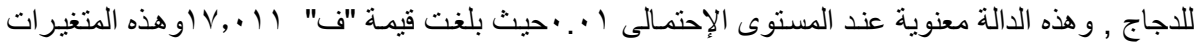

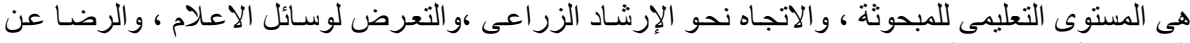

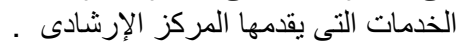

جدول (؛ Y): التحليل الارتباطى والاتحدارى المتعدد المراحل لعلاقة مستوى تبنى المبحوثنات بـالمتغيرات

\begin{tabular}{|c|c|c|c|c|c|}
\hline & & & & \\
\hline |قيم f المحسوبه لإختبّار & $\begin{array}{l}\text { المفسربن } \\
\text { اللتباين }\end{array}$ & 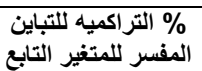 & معامل الإرتباط & المتغير الداخل فى التحليل & P \\
\hline \multirow{4}{*}{17.011} & 21.1 & $r 1.1$ & 0.297 & المستوى التعليمى للمبحوثه & 1 \\
\hline & 6 & 27.1 & 0.280 & الإتجاه نحو الإرشاد الزراعى & $\vec{Y}$ \\
\hline & 3.2 & 30.3 & 0.239 & السن السن & $r$ \\
\hline & 3.2 & 33.5 & 0.225 & |الإرشادى عن الخدمات التى يقدمها المركز & $\xi$ \\
\hline
\end{tabular}


وبناءاً على النتائج السابقة فإنه يتبين أن بعض المتغيرات المستقلة تسهم إسهاماً معنوياً فى تفسير التباين

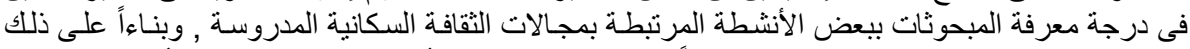

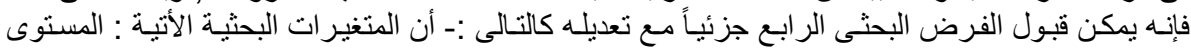

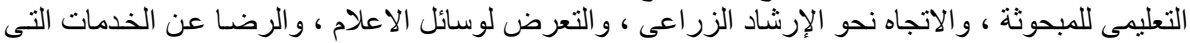

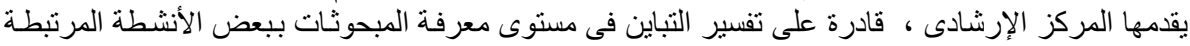

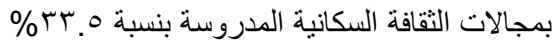

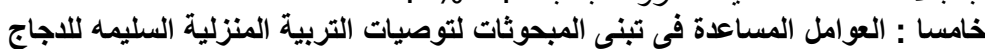

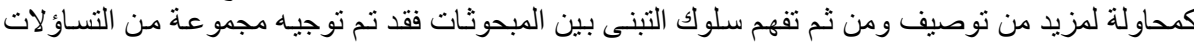

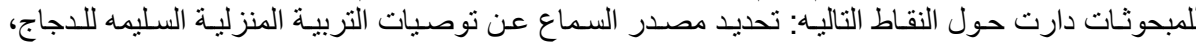

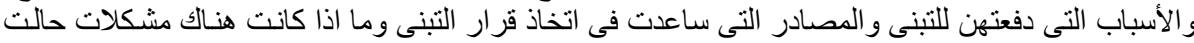

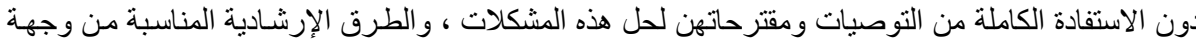

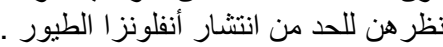

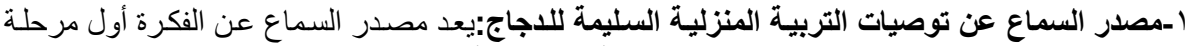

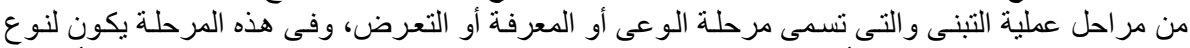

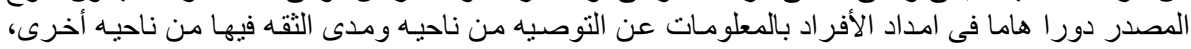

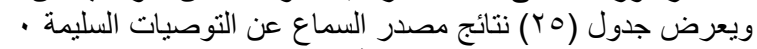

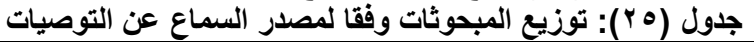

\begin{tabular}{|c|c|c|c|c|c|}
\hline$\%$ & 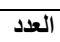 & مصدر السماع & $\%$ & العدد & مصدر السماع \\
\hline$\varepsilon$. & 07 & | لم-الجيران & 90.1 & $1 \pi \varepsilon$ & ـ ـ التليفزيون \\
\hline rY.10 & $\leqslant 0$ & |ٓ-الزوج & A. & $11 Y$ & r- الطبيب البيطرى \\
\hline$r$. & $\varepsilon r$ & | ب الر اديو & $\mathrm{v}$. & 91 & بـالمرشدة الزر اعية \\
\hline ro & ro & 1-1الأبناء & $\varepsilon_{0}$ & ז & الأصدقاء و الأقارب \\
\hline
\end{tabular}

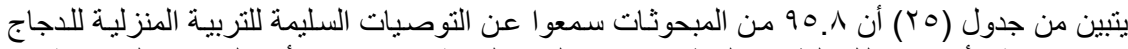

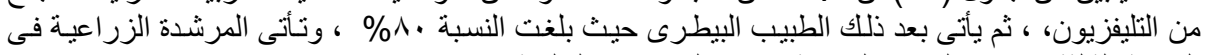

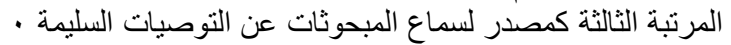

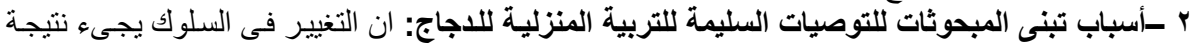

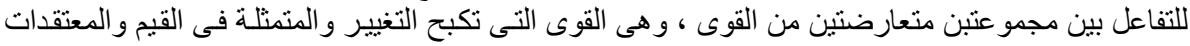

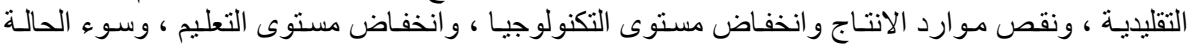

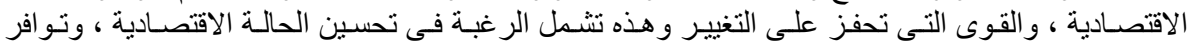

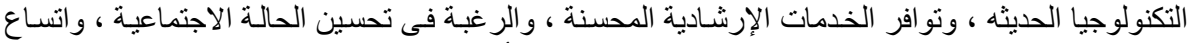

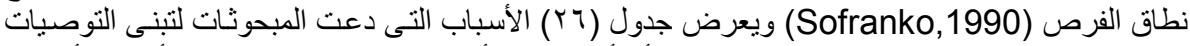

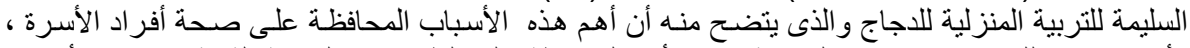

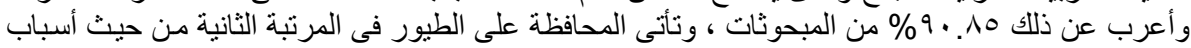

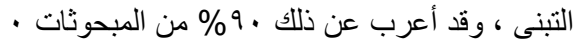

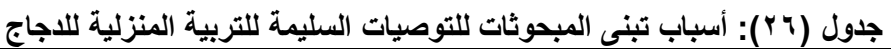

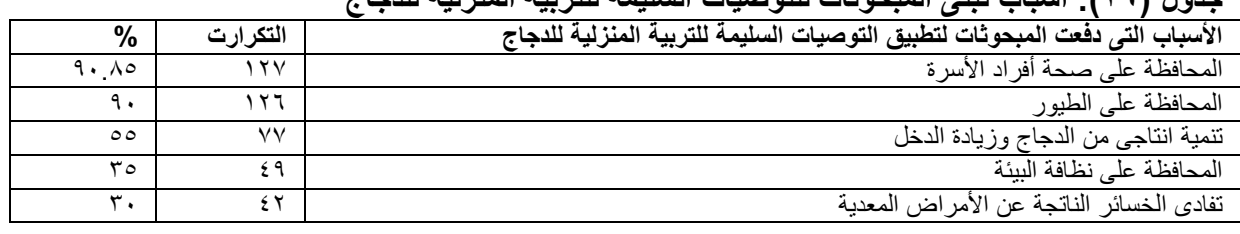

r- مصدر المساعدة فى اتخاذ قرار التبنى للتوصيات السليمة للتربية المنزلية للاجاج:

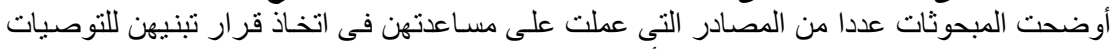

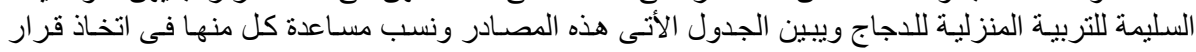


El-Zarka, Z. M. et al.

جدول (rV) توزيع المبحوثات وفقا لمصدر المساعدة في اتخاذ قرار التبنى

\begin{tabular}{|c|c|c|}
\hline$\%$ & 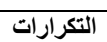 & 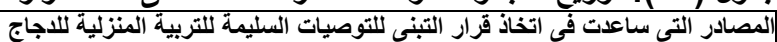 \\
\hline A. & $\pi r$ & |الوحدة البيطرية \\
\hline $\mathrm{v}$. & 91 & الإرشاد الزراعى \\
\hline$\leqslant 0$ & $\pi$ & الأصدقاء و الأقارب \\
\hline$\varepsilon$. & 07 & 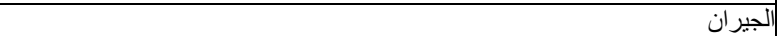 \\
\hline Tr. 10 & $\leqslant 0$ & | الززوج \\
\hline ro & ro & |لأبناء | (الاء \\
\hline
\end{tabular}

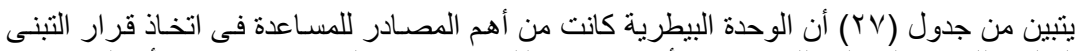

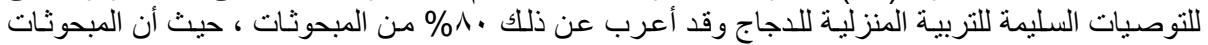

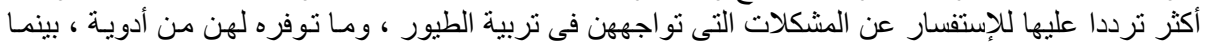

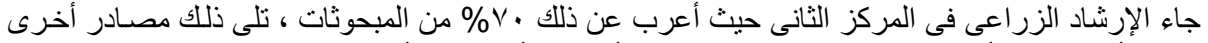

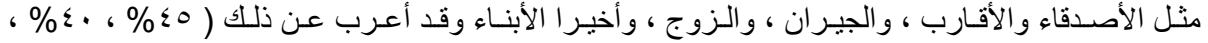
. 10

عـ المشكلات التى حالت دون الاستفادة الكاملة من التوصيات ومقترحاتهن للتظلب على هذه المشكلات:

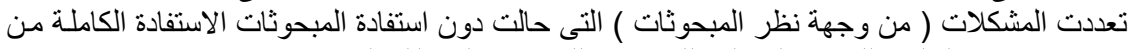

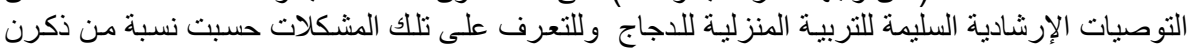

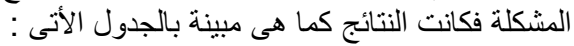

جدول (^^): توزيع المبحوثات وفقا للمشكلات التى حالت دون الاستفادة الكاملة من التوصيات

\begin{tabular}{|c|c|c|c|}
\hline$\%$ & التكرار & | - ت المشكلات & \\
\hline 9 . & $1 T_{4}$ & 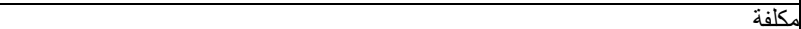 & \\
\hline 10 & 119 & عدم مر اعاة المرشد أو المرشدة لامكانيات وظروف المر أة الريفية. & \\
\hline$V T . \varepsilon$ & $1 \cdot r$ & عدم متابعة المرشدات الزر اعبات للمر أة الريفية عند تنفيذها لهذة التوصيات. & \\
\hline$v 1.1$ & $1 \cdots$ & صعوبة التطبيق • & $\varepsilon$ \\
\hline $\mathrm{v}$. & 91 & عدم وجو د مرشدات زر اعبات بالعدد المطلوب. & \\
\hline $7 \cdot . \mathrm{V}$ & 10 & غياب مستلزمات تتفيذ التوصيات السليمة للتربية المنزلية للاجاج عن الجمعيات الزر اعية. & 7 \\
\hline$\varepsilon \varepsilon . Y$ & $\pi T$ & ضعف ثقة الريفيات بالمرشدات الزر اعيات. & $\bar{V}$ \\
\hline$\varepsilon \varepsilon . Y$ & 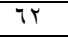 & عدم تخصص المرشد أو المرشدة فى الانتاج الداجنى وبخاصة أمر اض الدجاج & \\
\hline$\sum \varepsilon . Y$ & $7 T$ & قصور المعلومات الارشادية والايضاحات العملية بشأن تجهيز و استخدام هذه التقنيات. & 9 \\
\hline$\sum Y . Y$ & 09 & عدم وضوح الرسائل الإرشادية ووصولها فى الوقت غير المناسب للمر أة الريفية & $1 \cdot$ \\
\hline r9. & \&1 & عدم الاقتناع أصلا بالتوصيات السليمة للتربية المنزلية للاجاج. & 11 \\
\hline r9.r & $\varepsilon 1$ & الاعتقاد الر اسخ بجدوى الطرق التقليدية للتربية المنزلية للاجاج· & TY \\
\hline ro & ro & عدم المعرفة الكاملة للمرشد أو المرشدة الزر اعية للتوصيات السليمة للتربية المنزلية للاجاج & 14 \\
\hline ro & To & عدم وجود وقت فر اغ لدى الريفيات للتعرف على الجديد فى مجال تربية الدجاج · & 1 I \\
\hline
\end{tabular}

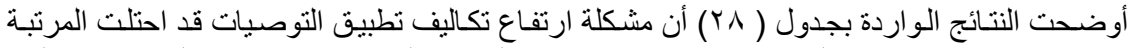

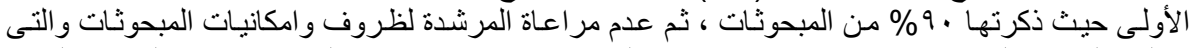

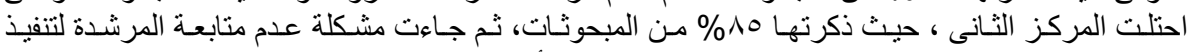

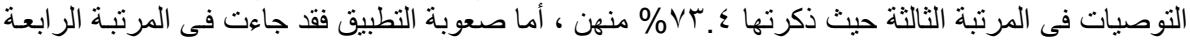

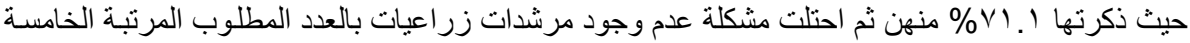

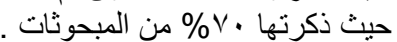

مقترحات المبحوثات لإتباع التوصيات السليمة للتربية المنزلية للاجاج للحد من انتثار أنفلونزا الطيور

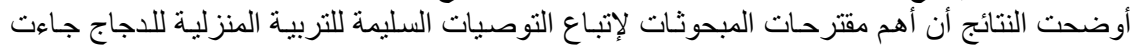

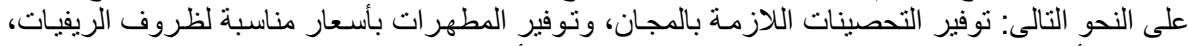

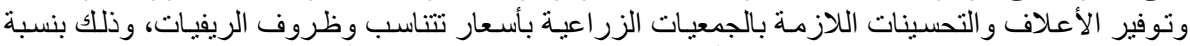

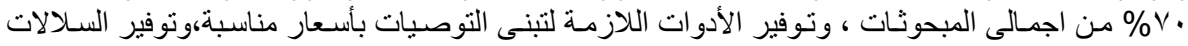
الجيدة ،ومتابعة المرشدات و الطبيب البيطرى لتنفيذ التوصيات حيث ذكرتها ( من المبحوثات على الترنيب. 
هـ الطرق الارشادية المناسبة للحد من انتشار أنفلونزا الطيور من وجهة نظرالمبر المبحوثات:

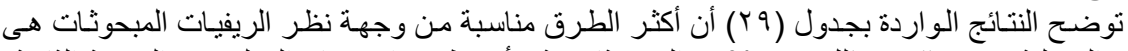

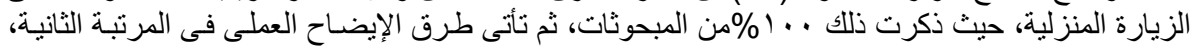

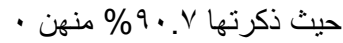

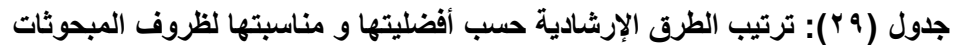

\begin{tabular}{|c|c|c|}
\hline$\%$ & التكرار & |الطريقة الارشادية \\
\hline $1 \ldots$ & $1 \leqslant$. & |الززيارة المنزلية \\
\hline $9 . . v$ & ITV & |الايضاح العملى \\
\hline $7 . . \mathrm{V}$ & 10 & الاجتماعات الارشادية \\
\hline 00 & VV & |الملصقات الرشادية \\
\hline ro & ro & |النشر ات الارشادية \\
\hline
\end{tabular}

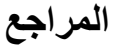

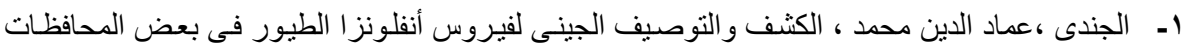

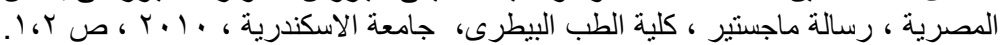

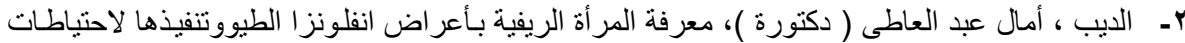

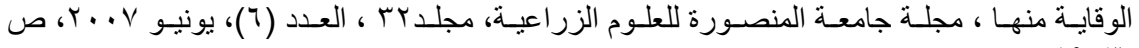
ह90\%:

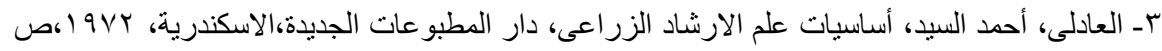
. r. 9

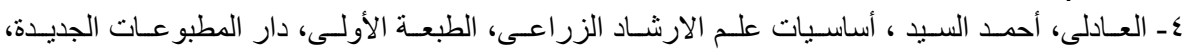

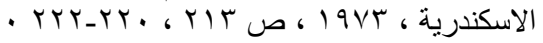

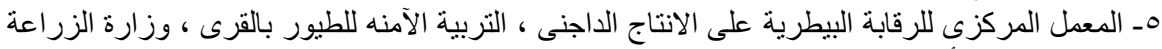

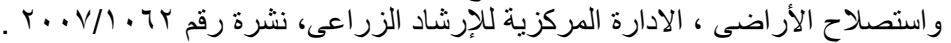

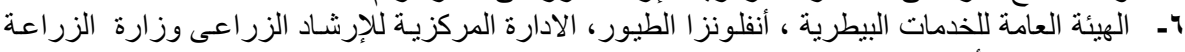

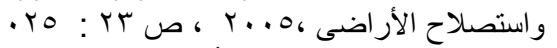

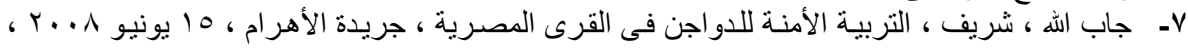

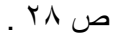

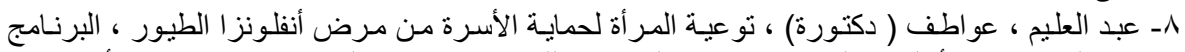

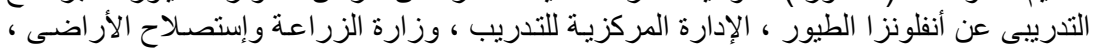

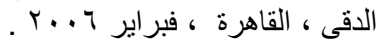

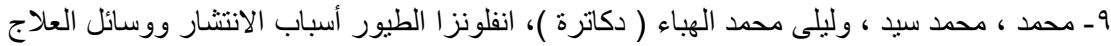

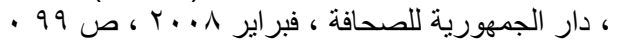

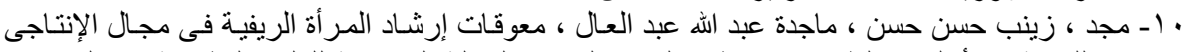

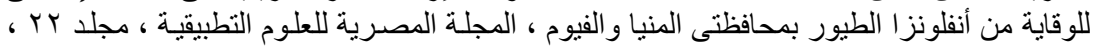

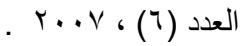

1 ا ـ مركز المعلومات وددعم اتخاذ القرار ، الجهاز المركزى للتعبئة العامـة والإحصـاء ، بيانات غير منشورة r...

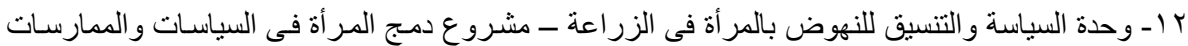

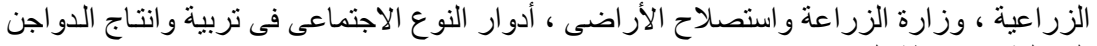

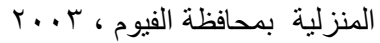
http://213,158,162,45h

http://www.alhadeeqa.com/vb/showthread.php?t=1902 http://www.as7apcool.com/vb/showthread.php?t=230812 
http://www.compas.gov.eg/page $=268$

http://www.dakahliaikhwan.com/viewarticle.php?id

http://www.libya alyoum.com/look/article? Idlanguage=178Idp..2008-

http://www0capmas0gor0eg

Qamar, M. Kalim ( 2005). Modernizing Agricultural Extension Systems: A pratical guide for policy- makers of developing countries. Food and $A$ gricultural Organization of the United Nations (FAO) Rome. P1.

Sofranko , A. J . in , Burton , E.Swanson (ed), Agriculture Extension , Areference Manual ( $2^{\text {nd }}$ edit $)$, FAO ,Rome , ( 1984) .

\title{
RURAL WOMEN S ADOPTION OF SAFETY HOME BREEDING RECOMMENDATIONS OF CHICKENS TO LIMIT BIRDS FLU SPREAD IN TWO VILLAGES IN EL BEHIRA GOVERNORAT \\ El-Zarka, Z. M. and A. A. A. Fayed and M. I. A.Hassan \\ Faculty of Agricultural , Damanhour University
}

\begin{abstract}
The stady aimed mainly at identifying the rural women's adoption of safety home breeding recommendations of chickens to limit birds flu spread in two villages in ELBehira governorate .Data were collected by personal interviews using Apre-test questionnaire from 140 respondents chosen randomly from 2 villages in Hosh Essa district percentage, mean, stander deviation and frequencies were used to describe and classified respondents according to their characteristics, simple correlation,stepwise multiple regression were used to analyze data statistically.

The major findings were as follows :

$1-20 \%$ and $45.72 \%$ of the respondents have a low and average standerd of knowledge of recommendations .

$2-24.15 \%$ and $48.55 \%$ of the respondents have a low and average standerd of adopting the recommendations.

3- There were appositive relationship between knowledge standar and all of education level, aim of breeding,cosmopoliteness, leadership, satisfaction with the service which the guidance center offers, Mass Media exposure and attitudes towards agriculture extension, multiple reference sources and the satisfication about services which the agricultural community.

4- There were appositive relationship between adoption to the right recommendations of raising chickens and all of level of education, aim of breeding, cosmopoliteness, leadership, satisfaction with the services which are offered by different centres,exposing to Mass Media and attitudes towards agriculture extension.

5-The most important hindrances of adoption are lack of knowledge, diffculty of applying and raising the cost.

6- There are 6 independent variables interpret about $54.2 \%$ of total variance in the knowledge degree at 0.01 significance level they are :educational level ,attitudes towards agriculture extesion, aim of breeding, Mass Media exposure ,leadership,statisfaction with services
\end{abstract}


7- There are four indpendent factors . which are responsible for explaining $33.5 \%$ of varying in adopting the right recommendations of raising chikens by the ruler women they are level of education, attitudes towards agriculture extesion , satisfaction with the services and Mass Media exposure.

كلية الزراعة ـ جامعة المنصورة

كلية الزراعة - جامعة الاسكندرية - جاعنة

\author{
قام بتحكيم البحث

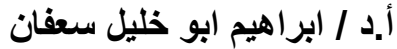 \\ أ.د / أد / محمد محمد عمر الطنوبى خلئ
}

